\title{
EL EJERCICIO JURISDICCIONAL EN EL ESPACIO DOMÉSTICO REGIO: LA RELACIÓN DEL DESEMBARGO DO PAÇOY LA CASA DA SUPLICAÇÃO CON LA CÂMARA REAL PORTUGUESA (1557-1583).
}

\author{
Ignacio Ezquerra Revilla \\ (Instituto Universitario La Corte en Europa-Universidad Autónoma de Madrid y \\ Centro de Investigação e Desenvolvimento sobre Direito e Sociedade-Universidade \\ Nova de Lisboa) ${ }^{1}$. \\ ignacio.ezquerrarevilla@gmail.com
}

\section{RESUMEN}

En las últimas décadas, la interpretación del espacio palaciego se ha abierto a nuevos aspectos más allá de lo formal. Se ha entendido como un ámbito de acceso gradual a la persona real, en cuyo recinto más reservado (la Cámara Real) compatibilizaba la dimensión personal y la administrativa. Esto implicaba, de hecho, la asimilación en este último de los órganos jurisdiccionales, que quedaban así tocados por una naturaleza doméstica. Como se trata en este artículo -a través del uso principalmente de fuentes cronísticas, legislativas y otras investigaciones-, la monarquía portuguesa no escapó a este esquema y el Desembargo do Paço y la Casa da Suplicação mantuvieron diferentes grados y formas de integración con ese espacio entre el inicio del reinado de João II (1481) y el regreso de Filipe I a Castilla (1583). Paradójicamente, las medidas que este último tomó entonces implicaron la revitalización de unas prácticas jurisdiccionales cuya pervivencia había sido perjudicada por la inestabilidad política propia de los reinados de D. Sebastião y D. Henrique. Sólo el estudio sistemático de más fuentes primarias podrá confirmar lo planteado en este trabajo.

PALABRAS CLAVE: Espacio palaciego; Desembargo do Paço; Casa da Suplicação; Audiencia Real; Cámara Real.

\section{THE JURISDICTIONAL EXERCISE IN THE ROYAL DOMESTIC SPACE: THE RELATIONSHIP OF THE DESEMBARGO DO PAÇO AND THE CASA DA SUPLICAÇÃOWITH THE PORTUGUESE CÂMARA REAL (1557-1583).}

\section{ABSTRACT}

In last decades, the interpretation of the palatial space has opened up to new aspects beyond the formal. It has been understood as a field of gradual access to the royal person, in which most reserved enclosure (the Royal Chamber) he made

\footnotetext{
${ }^{1}$ Homenagem provisória à memoria do Professor Doutor António Manuel Hespanha, à espera de maiores frutos.
} 
compatible the personal and administrative dimension. This implied, in fact, the assimilation in it of the jurisdictional bodies, which were thus touched by a domestic nature. As it is address in this article -through the use mainly of chronistic and legislative sources, and other research works-, the Portuguese monarchy did not escape this scheme and the Desembargo do Paço and the Casa da Suplicação maintained different degrees and forms of integration with that space, from the beginning of the reign of João II (1481) to the return of Philip I to Castile (1583). Paradoxically, the measures that the latter took then involved the revitalization of jurisdictional practices which survival had been harmed by the political instability characteristic of the reigns of D. Sebastião and D. Henrique. Only the systematic study of more primary resources can confirm what is stated in this work.

KEY WORDS: Palatial space; Desembargo do Paço; Casa da Suplicação; Royal Audience; Royal Chamber.

Este trabajo reflexiona sobre la proyección espacial de las decisiones gubernativas y de la aplicación jurisdiccional en la Edad Moderna. El razonable cumplimiento de los mandatos en estos órdenes no dejaba de tener algo de llamativo, en sistemas político-administrativos en los que los medios materiales de la corona eran limitados. Para entender este hecho, pretendo examinar el proceso de integración y continuidad espacial que fue consumado a partir del espacio restringido del monarca (donde combinó sus facetas personales y administrativas) que cimentó todo un orden material de integración. En este proceso, que circunscribo aquí al ámbito de la monarquía portuguesa - con algunas referencias a la castellana-, la importancia de la institución genérica del Consejo fue crucial, dado que fue correa de transmisión mediante la cual las decisiones tomadas en aquella área restringida fueron implementadas en el espacio territorial.

El fundamento de una visión así es la conciencia sobre la interacción entre el gobierno doméstico regio y el general en las monarquías modernas. Inicialmente, esa percepción separó los dos espacios, la Casa (Household) y, por otro lado, la Corte y el Consejo. Pero la propia investigación permite deducir la imposibilidad de considerar herméticas estas dos áreas, en el caso de las monarquías cuya forma de gobierno envolvía, desde un principio, la extensión del gobierno de la Casa Real sobre la plataforma territorial representada por los reinos ${ }^{2}$. Esto fue consecuencia de la conjunción indistinguible de las dos dimensiones de la persona real, el personal y el

\footnotetext{
2 Otto Brunner, "La Casa Grande y la Oeconómica de la vieja Europa", en Nuevos caminos de la historia social y constitucional, Otto Brunner (Buenos Aires, 1976): 87-123; Jean Guillaume dir., Architecture et vie sociale. L'Organization intérieure des grandes demeues à la fin du Moyen Age et a la Renaissance (París: Picard, 1994).
} 
administrativo $^{3}$. Inevitablemente, esa circunstancia implicaba la existencia de un espacio palaciego restringido, aunque poroso, en el cual el monarca actuaba como persona y como gobernante, y un dispositivo administrativo que formalizaba tal expansión espacial del gobierno doméstico. Así, por un lado, se percibe la importancia de la Cámara Real. Y, por otro, la atención al Consejo debe ampliarse más allá de su dimensión judicial o ministerial, y enfocarse en su naturaleza interna y en su valor como instrumento para la señalada transferencia administrativa.

\section{LA CÁMARA REAL}

La propia construcción orgánica de las monarquías castellana y portuguesa fue resultado de un proceso espacial, dado que fue completándose al tiempo que culminaba la adquisición territorial al poder musulmán ${ }^{4}$. Amenaza militar e inestabilidad política dieron a la Corte algunas características derivadas de su itinerancia ${ }^{5}$ que, en sustancia, nunca perdió, aunque en la Edad Moderna ofreciese pruebas de un asentamiento estable (en Madrid en el caso castellano, en Lisboa en el portugués). Al tiempo que continuaba vigente un sentido implícito o metafórico de Corte, expresado en una serie de símbolos o manifestaciones administrativas que, a través de la transubstanciación de la persona real ${ }^{6}$, dejaron claro que la Corte no era sólo el lugar de residencia del rey, sino que también tendía a expandirse a través de la superficie territorial del respectivo reino. El núcleo original de expansión de la Corte fue el Palatium Regis y la Cámara Real ${ }^{7}$. Expansión de la Corte pero también doméstica, puesto que ambas dependencias constituían, en sustancia, dos etapas cronológicas sucesivas de la misma área reservada en la cual el rey conciliaba su naturaleza personal y su dimensión política.

\footnotetext{
${ }^{3}$ Ernst H Kantorowicz, Los dos cuerpos del rey: un estudio de teología política medieval (Madrid: Alianza Editorial, 1985).

${ }^{4}$ En Portugal, concluida la Reconquista mediado el siglo XIII, comenzó también con anterioridad el proceso de consolidación administrativa de la monarquía. La línea del Tajo se alcanzó en 1147, el territorio correspondiente al actual Alentejo en 1168, y el proceso fue completado con la conquista del Algarve en 1249.

${ }^{5}$ Rita Costa Gomes, "Les déplacements de la Cour portugaise: deux axiomes et quatre hypothèses pour une comparaison des monarchies iberiques", e-Spania, no. 8 (2009), http://espania.revues.org//8853.

${ }^{6}$ José Manuel Nieto Soria, "La transpersonalización del poder regio en la Castilla bajomedieval", Anuario de Estudios Medievales 17 (1987): 559-570; Javier Portús Pérez, "El retrato vivo: fiestas y ceremonias alrededor de un rey y su palacio", en El Real Alcázar de Madrid: dos siglos de arquitectura y coleccionismo en la Corte de los reyes de España, dir. Fernando Checa (Madrid: Comunidad de Madrid-Nerea, 1994).

${ }^{7}$ Claudio Sánchez Albornoz, "El Palatium Regis asturleonés”, Cuadernos de Historia de España 59-60 (1976), 5-77; Luis Suárez Fernández, “Origen y evolución del Palacio Real en la Edad Media”, en VV.AA., Residencias reales y Cortes itinerantes (Madrid: Patrimonio Nacional, 1994), 27-34; Andrés Gambra Gutiérrez, "El Palatium y la Domus Regis castellanoleoneses en tiempos de la dinastía pamplonesa", en Evolución y estructura de la Casa Real de Castilla, I, coords. Idem-Labrador Arroyo, Evolución y estructura de la Casa Real de Castilla, I (Madrid: Polifemo, 2010), 11-63.
} 
El surgimiento y la consolidación de la Cámara en el espacio doméstico real, como el área reservada del rey, donde desarrolló su vida cotidiana y maduró la diseminación de la gracia y la tarea de gobierno, fue común a todas las monarquías europeas. Los usos palatinos de las monarquías francesa e inglesa compartían un ámbito cultural con la Casa de Borgoña, en un proceso en el que cambiaban experiencias y procedimientos. La Cámara era el espacio para la relación diplomática entre las dos monarquías, y también sus respectivas instituciones jurisdiccionales tenían una conexión más o menos clara con ella, dado que de la Cámara emanaba un sentido de integración de la estructura jurisdiccional en el orden interno real, que facilitó el control político ${ }^{8}$.

Pero estos eran también los trazos propios de las monarquías portuguesa y castellana $^{9}$, originadas en un contexto común de raíz visigótica. En Portugal, la distinción esencial en esta combinación espacial era la significada entre la Sala (Sala Grande) como ámbito resultante del encuentro del rey y sus vasallos y servidores, y la Antecâmara como espacio de separación y control de acceso a la propia persona real ${ }^{10}$. Como explica Rita Costa Gomes, en la Corte portuguesa, después de una fase inicial en la que la repostería desempeñó parte de sus funciones, la Cámara ganó importancia a partir del siglo XIV, en un proceso general de especialización funcional en su seno, que resultó en una distribución espacial en el palacio. Es posible apreciar la disposición de la Sala, Câmara, Capela, Reposte, Guardaroupa e Cozinha. La principal diferencia estructural en ese conglomerado de espacios fue la visible entre la Sala y la Câmara, o, más exactamente, la serie de Câmaras que la integraba, evidente al final de la Edad Media. En su Leal Conselheiro, el rey Duarte describía esa serie de Câmaras como constituida por la Sala, la Câmara de Pará o Antecâmara, la Câmara de Dormyr, la Trescâmara y el Oratório -estructura a la que se ajustó el Palacio de Sintra o el Paço da Ribeira lisboeta-, diferenciadas por reglas ceremoniales de proximidad ${ }^{11}$. Estas implicaban una

\footnotetext{
${ }^{8}$ Jean Francois Solnon, La Cour de France (s.l., 1987); David Starkey, The english Court from the Wars of the Roses to the Civil War (Singapore, 1987).

9 Pedro Cardim, "A Corte régia e o alargamento da esfera privada", en História da Vida Privada em Portugal. A Idade Moderna, coord. Nuno Gonçalo Monteiro, II (Lisboa: Círculo de Leitores, 2011), 160202. Ignacio Ezquerra Revilla "La Cámara", en La monarquía de Felipe II: la Casa del Rey, I, dirs. José Martínez Millán-Santiago Fernández Conti, La monarquía de Felipe II: la Casa del Rey, I (Madrid: Fundación MAPFRE: 2005), 121-142; Ignacio Ezquerra Revilla, "La Cámara Real como espacio palaciego de integración", en La Corte de Felipe IV (1621-1665): reconfiguración de la Monarquía Católica, I, dirs. José Martínez Millán-José Eloy Hortal Muñoz (Madrid: Polifemo, 2015), 379-439.

${ }^{10}$ Rita Costa Gomes, The making of a Court Society: Kings and nobles in late medieval Portugal (Cambridge University Press, 2003), 47-312. Para esta autora, la Cámara era un órgano de la Corte «mettant en place des mecanismos de contrôle de l'accês au souverain», una configuración humana organizada alrededor de la presencia física del rey. Los oficiales que frecuentaban la Cámara Real eran auténticas correas de transmisión que hacían posible la articulación de un sistema complejo y estratificado, en el que las esferas de acción de los distintos agentes se superponían, Rita Costa Gomes, "Le Conseil Royal au Portugal (1400-1520)", en Conseils et conseillers dans l'Europe de la Renaissance, v. 1450-v. 1550, ed. Cedric Michon (Presses Universitaires François Rabelais de Tours- Presses Universitaires de Rennes, 2012), 147-174.

${ }^{11}$ Diogo Ramada Curto, "Ritos e cerimonias da monarquia em Portugal (séculos XVI a XVIII)", en A memória da nação: colóquio do Gabinete de Estudos de Simbologia, Francisco Bethencourt y Diogo Ramada Curto (Lisboa: Livrária Sa da Costa, 1991) 201-265.
} 
jerarquización de la sociología palaciega determinada por el lugar en el que se producía el contacto con la persona real, antes que por la aplicación de una dualidad público/privado, concepto contemporáneo de difícil aplicación a la época. El referido texto graduaba la entrada tenida con el rey en la Cámara con un símil de orden afectivo ${ }^{12}$, mientras en Castilla parecía depender de un ceremonial basado en la administración de la maiestas regia ${ }^{13}$. «Julgamos que a ideia de proximidade física da(s) pessoa(s) reai(s), funcionando como factor de distinção, ou seja, a gestão da acessibilidade da pessoa real, pode ser mais explicativa que a oposição entre público e privado», afirma el profesor Nuno Senos ${ }^{14}$.

La diferencia entre Sala y Antecámara es una característica que también pudo ser apreciada en el caso castellano, donde, al tiempo, las Partidas pusieron al mismo nivel, entre los deberes del Camarero Mayor, el cuidado material del rey, y la guarda de las arcas con sus escritos ${ }^{15}$. La relación diplomática entre las dos monarquías permite también deducir que respondió al molde doméstico madurado y expandido en el seno de la Cámara Real. Este rasgo, derivado como digo de una común tradición de origen visigótico, se vio fortalecido por la influencia del ceremonial borgoñón, que regía el servicio del emperador, pero que también se apreció en la recepción de embajadores extranjeros en la Corte de João III. Si Dom Manuel los recibía en la Sala Grande, y sólo caso de tratar con mayor profundidad algún punto concreto pasaba con ellos a la Antecâmara, la práctica cambió en tiempo de su hijo. Desplazado el embajador Luis de Silveira a Castilla para felicitar a Carlos V por su regreso de Flandes, a su vuelta Dom João III comenzó a recibir a los representantes extranjeros del mismo modo que el emperador había recibido a su embajador: en pie y directamente en la Antecámara, «na Câmara grande que está alem da Sala» ${ }^{16}$.

12 «Pera mayor declaraçam de como entendo que devemos aver das cousas sentimento virtuosamente, eu conssiiro no coraçom de cadahuum de nos cynquo casas, assy ordenadas como custumam senhores. Item prymeira, salla, em que entram todollos do seu senhorio que omyzyados nom som, e assy os estrangeiros que a ella querem vîir. Item segunda, camara de paramento, ou ante-camara, em que custumam estar seus moradores e alguums outros notavees do reyno. Item terceira, camara de dormyr, que os mayores e mais chegados de casa devem aver entrada. Item quarta, trescamara, onde se custumam vestir, que pera mais speciaaes pessoas para ello perteecentes se devem apropiar. Item quinta, oratorio, em que os senhores soos algumas vezes cadadia he bem de see apartarem pera rezar, leer per boos livros, e pensar em virtuosos cuidados», transcrito em Nuno Senos, O paço da Ribeira: 1501-1581 (Lisboa: Editorial Notícias, 2002), 119.

${ }^{13}$ Fernando Checa, "Un príncipe del Renacimiento. El valor de las imágenes en la Corte de Felipe II", en Felipe II. Un monarca y su época. Un príncipe del Renacimiento, Idem, dir. (Madrid: Sociedad Estatal para la Conmemoración de los Centenarios de Felipe II y Carlos V, 1998), 25-56 y 26.

14 Senos, O paço, 120.

${ }^{15}$ Jaime de Salazar y Acha, La Casa del Rey en Castilla y León en la Edad Media (Madrid: Centro de Estudios Constitucionales, 2000); María del Cristo González Marrero, La Casa de Isabel la Católica (Ávila: Institución Gran Duque de Alba, 2005).

${ }^{16}$ Así serían recibidos sendos embajadores del propio emperador, Monsieur de La Chaulx y el Doctor Cabrero, cuando se desplazó a recoger a doña Leonor de Austria, Francisco de Andrade, Crónica de D. João III. Intr. y revisión de M. Luis de Almeida (Porto: Cello e irmão, 1976) capítulo XXV. Al respecto, también, Senos, O paço, 141. 
Es importante subrayar que, como destacamos, la Cámara no era sólo un conglomerado de servicio sino, sobre todo, un espacio en el que coincidían y se superponían diferentes dimensiones y actividades de la persona real. Un hecho de tan profundo calado no ha recibido la atención que merece, quizá, por la prioridad conferida en su tiempo por la historia de la arquitectura palaciega al análisis estilístico de las fachadas o a otros aspectos relacionados con la apariencia exterior de los edificios analizados. Sin embargo, para Nuno Senos, el descubrimiento de los interiores, tanto en un sentido decorativo como -sobre todo- organizativo, se ha mostrado como una herramienta metodológica de primer orden ${ }^{17}$, cuyos primeros esbozos se debieron a un trabajo pionero de Hugh Baillie y un coloquio organizado por el Centre d'Etudes Supérieures de la Renaissance en Tours en $1988^{18}$. Tales aportaciones abrieron un camino que permite valorar relaciones adicionales en un espacio del que hasta cierto momento preocupó sobre todo su apariencia, empezando por su función asimiladora del contorno territorial, aspecto en el que las contribuciones de Marcello Fantoni y Jeroen Duindam son de importancia capita ${ }^{19}$. Este esfuerzo historiográfico, al que cabe añadir la formulación, principalmente desde las ciencias geográficas, del denominado Spatial Turn ${ }^{20}$, ha conferido un merecido protagonismo al espacio, en un sentido comprensivo y cohesivo.

\section{CONTACTO DEL DESEMBARGO DO PAÇO Y LA CASA DA SUPLICAÇÃO CON LA CÂMARA REAL. IDENTIFICACIÓN Y UNICIDAD CON LA DIMENSIÓN JURISDICCIONAL DE LA PERSONA REAL}

A pesar de las evidencias implícitas (como su calidad como espacio para el acceso al rey, para la tarea jurisdiccional o la transferencia documental), los historiadores no han tendido a aproximarse al estudio de la Cámara Real desde el punto de vista genérico de su potencial administrativo. Y ello, pese a la vigencia en la Edad Moderna de un gobierno de orden doméstico y dimensión espacial, que daba cohesión al territorio, por medio del cumplimiento de los deberes oeconómicos del rey ${ }^{21}$. Una

\footnotetext{
${ }^{17} \mathrm{Al}$ respecto, Senos, O paço, 27.

${ }^{18}$ Hugh Murray Baillie, "Etiquette and the planning of the state apartments in baroque palaces", Archaelogia or Miscellaneous Tracts relating to Antiquity 101 (1967) 169-199; dir. Jean Guillaume, Architecture et vie sociale, op. cit. Continuación de esta línea son las investigaciones aportadas por la red PALATIUM, Court Residences as Places of Exchange in Late Medieval and Early Modern Europe (1400-1700), financiada la European Science Foundation, en la que está integrado el profesor Nuno Senos.

19 Caso de sus trabajos en Marcello Fantoni, George Gorse y Malcolm Smuts, The Politics of Space: European Courts, ca. 1500-1750 (Roma: Bulzoni Editore, 2009).

${ }^{20}$ Sobre este concepto, Barney Warf, Santa Arias, eds., The Spatial Turn: Interdisciplinary perspectives (London and New York: Routledge, 2009).

${ }^{21}$ Otto Brunner, "La Casa Grande". Daniela Frigo, Il padre di famiglia. Governo della casa e governo civile nella tradizione del 'economica' tra Cinque e Seicento (Roma: Bulzoni, 1985); António Manuel Hespanha, Visperas del Leviatán. Instituciones y poder político (Portugal, siglo XVII) (Madrid: Taurus, 1989); Daniela Frigo, "Disciplina Rei Familiariae: a economía como modelo administrativo de Ancien Régime", Penélope. Faz̧er e desfazer a História 6 (1991): 47-62.
} 
investigación de esta clase hace posible abordar un sentido administrativo de la Corte muy alejado de lo meramente ceremonial o institucional. Por esta vía, nuestro conocimiento de los órganos jurisdiccionales adquiere un perfil más fiel a su origen y papel en el inicio de la Edad Moderna, un instrumento para la prolongación del gobierno doméstico regio hacia el territorio, de clara intención inclusiva. El punto crucial es aclarar el proceso de toma de decisiones desde su maduración en el ámbito más reservado del rey hasta su articulación en el territorio, a través de la figura genérica del Consejo.

El Consejo ejercía una función transmisora, amplificadora del espacio doméstico del rey al espacio de los reinos. Difundía el concepto cortesano más allá de límites políticos o administrativos, no en un sentido tradicional, interesado por la formalidad del ceremonial o el oropel. Sino como una suerte de trama carismática emanada del rey y de orden supra e interjurisdiccional que, al mismo tiempo que materializaba la posesión patrimonial del territorio de cada uno de sus reinos por parte del monarca, favorecía su cohesión y gobierno y lo convertía en plataforma de un complejo desarrollo administrativo que en gran medida está todavía por descubrir.

$\mathrm{Al}$ margen de los aspectos más generales, recogidos por ejemplo en las etiquetas que regulaban el uso del espacio palaciego y las prácticas ceremoniales que acogía, sabemos muy poco sobre cómo funcionaba la Cámara en un sentido administrativo. En relación con este punto, y centrado en los casos ibéricos, hay señales tanto en el castellano como en el portugués de la integración de los órganos jurisdiccionales en la domesticidad real ${ }^{22}$. En el primero de ellos tal vez la más importante fue la celebración de la llamada Consulta de los Viernes, que reunió al rey con el Consejo, en la antecámara real. Hay muchos aspectos que todavía deben ser conocidos en esas consultas, cuya celebración tuvo frecuencia desigual durante la Edad Moderna, según la paulatina mudanza de los fundamentos doctrinales de la monarquía ${ }^{23}$

Era una práctica administrativa compartida por ambas monarquías, que asimilaba hasta tal punto sus órganos jurisdiccionales - principalmente el Desembargo do Paşo y el Consejo Real de Castilla- en el espacio doméstico más propio de su respectivo rey, que quedaban unificados e identificados como trasunto jurisdiccional colegiado de la propia persona real. Esta conjunción con ella era además fortalecida por la eminencia de la función jurisdiccional entre las potestades de la majestad real, avalada por el organicismo político de molde aristotélico-tomista que teorizaba sobre la función real, y daba al monarca el papel de cabeza o centro del sistema político-administrativo, reflejo de la posición de Dios en el universo. Principios que fueron recogidos en el ordenamiento que regulaba el funcionamiento de los organismos jurisdiccionales. El

22 Gomes, "Le Conseil Royal au Portugal (1400-1520)"; José Martínez Millán, “Conseillers et factions curiales pendant le règne de l'empereur Charles Quint (1500-1558)", ed. Michon, Conseils et conseillers, 129-145.

${ }^{23}$ Con todo, el caso castellano va siendo objeto de atención tanto empírica como interpretativa, Ignacio Ezquerra Revilla, El Consejo Real de Castilla en el espacio cortesano (siglos XVI-XVIII) (Madrid: Polifemo, 2017); Regina Polo Martín, Consejos y consultas: la consulta como instrumento de gobierno en la monarquía bispana del Antiguo Régimen: un estudio jurídico institucional con especial referencia al Consejo de Castilla (Madrid: Fundación BBVA, 2018). 
regimento conferido a la Casa de Suplicaşão durante el segundo cuarto del siglo XV, abría su capítulo referido al Consejo de Justicia de forma que no dejaba duda al respecto:

Diz o Senhor Deus (Isaias, 45): Minhas são as justiças, meu é o poder. Destas palavras conclui-se perfeitamente que qualquer outro que tem a justiça e o poder, tem-nos de Deus, e não exerce o que é seu, mas o que é de Deus. Contudo, o próprio Deus, para maior afirmação, disse: Por mim reinam os reis, e os poderosos exercem a justiça. Logo, o Rei é o vigario de Deus ${ }^{24}$.

Conforme a la citada disposición, esta naturaleza de vicario de Dios en las cosas temporales debía traducirse en una armonía general encaminada a la felicidad de los súbditos, remitiendo a lo expresado por San Cipriano, padre de la Iglesia, en De duodecim abusivis que, en definitiva, mencionaba las funciones tuitivas, paternales y protectoras reservadas al rey en el referido sistema filosófico ${ }^{25}$. Igualmente, en lo relativo al regedor (presidente), la reglamentación de la Casa declaraba ser «a justiça... a causa mais principal por que com a graça de Deôs por ela reynamos, e a ela sobre todalas cousas desta mundo tenhamos por isso mayor obriguaçam, pera com equidade sempre a guardarmos a todos» ${ }^{26}$. En la misma línea, en las Ordenações Manuelinas el ejercicio de la justicia por parte del rey era esencial «para boa governança, e conservação de toda República, e Estado Real» $»^{27}$.

En su De regimine príncipum ${ }^{28}$, Santo Tomás concebía el gobierno monárquico como la forma propia para el cumplimiento de tales funciones de orden oeconómico, mediante una articulación de metáforas de orden orgánico, intelectual, natural y divino que desembocó en una concepción corporativa de la sociedad, transposición del cuerpo místico representado por la Iglesia, visible en las Partidas o el Fuero Real. Conforme a lo señalado por Ana Isabel Buescu, la evolución de esta línea de pensamiento tuvo hitos en Portugal como la Carta a El rei Nosso Senhor de Francisco de Sá de Miranda, los discursos de Francisco de Melo en la apertura de las Cortes de Torres Novas y Évora (1525 y 1535) o el tratado dedicado por el capellán y predicador real Francisco de Monzón a João III sobre el oficio real y la república perfecta en $1545^{29}$, que volveré a citar. El Desembargo do Paço fue visto como la encarnación institucional de tales principios filosóficos, según se aprecia en Lustre ao Dę̧mbargo do Paço, obra de João

${ }^{24}$ Martim de Albuquerque, O Regimento Quatrocentista da Casa de Suplicação (texto latino acompanhado de tradução portuguesa pelo Dr. Miguel Pinto de Meneses) (París: Arquivos do Centro Cultural Português, 1980), 41.

25 «A justiça do Rei é a paz dos povos, a tutela da pátria, a imunidade da plebe, a defesa da nação, o cuidado das fraquezas, a alegria dos homens, a temperança do mar, a serenidade do ar, a fecundidade da terra, a consolação dos pobres, a herança dos filhos, e, para sí mesmo, a esperança da futura bemaventurança» Albuquerque, O Regimento, 27.

${ }^{26}$ Maria Themudo Barata, As regencias na menoridade de D. Sebastião. Elementos para uma bistória estrutural, I, (Lisboa: Imprensa Nacional-Casa da Moeda, 1992), 113.

${ }^{27}$ Ordenações Manuelinas (Lisboa: Fundação Calouste Gulbenkian, 1984), lib. I, 1.

28 Tratado del gobierno de los Príncipes, del Doctor Santo Tomás de Aquino, traducida en nuestra lengua castellana por Alonso Ordónez de Seijas y Tovar (Madrid: por Iuan González, 1625).

${ }^{29}$ Ana Isabel Buescu, D. João III (Lisboa: Círculo de Leitores-CEPCEP, 2014), 181-183. 
Pinto Ribeiro en la que se ponía en relación el origen divino de la acción de aconsejar (con el ejemplo de San Gregorio Niseno en De hominis opificio), su estrecha vinculación con la dignidad real y la superioridad jerárquica que tales circunstancias y su función oeconómica conferían al Desembargo, comparado con el resto de tribunales portugueses ${ }^{30}$.

Por todo ello, no debe sorprender que a lo largo de la maduración política de la monarquía portuguesa en el bajo medievo, el ejercicio judicial directo formase parte principal de las tareas del príncipe, momento mítico de su evolución que pervivió a la aparición de órganos jurisdiccionales, creados por el rey ante la necesidad de afrontar una tarea judicial más compleja y extensa ${ }^{31}$. La prioridad de conciliar función tan esencial de la naturaleza real con la nueva estructura creada se resolvió con la reunión conjunta del monarca con tales órganos, en la fase del procedimiento que, esencialmente, representaba esa función real: la resolutoria, encarnada por la sentencia ${ }^{32}$. Como resulta lógico, la implementación de la novedad implicó modificaciones en el uso del espacio en el que el monarca se desenvolvía, el Palacio Real, que respondieron a la naturaleza con que nacieron tales órganos. La Casa de Suplicação y los desembargadores do Paço (institucionalizados e independizados de la primera a partir de 1521) no implicaban una delegación o representación de la persona real en el terreno jurisdiccional, sino un ejercicio soberano solidario entre ellos y la persona real que se tradujo en la identificación entre ambos. Maria Themudo Barata ha definido acertadamente esta situación como «emanações da competencia da soberania, mais do que delegações de poder» ${ }^{33}$. Mientras António Manuel Hespanha subraya que la competencia del Desembargo era la propia competencia del rey,

${ }^{30}$ Lustre ao Dezembargo do Paço, e as eleições, e perdoens, pertenças de sua jurdição, Dao Ioão PInto Ribeyro. Em Lisboa. Com todas as licenças necesarias, Na celebre officina de Paulo Crasbeeck, Anno 1649. En esta obra se lee: «... como havia de entregar (Dios) ao homem o governo do mundo, quizlhe dar que imitar em sua divina magestade, \& ensinallo, q usasse de Conselho en suas acções, pera proceder com acerto \& prudencia nellas... Anda o Conselho tão encadeado com a dinidade real, q na lingua santa (hebreo) o mesmo verbo significa tomar conselho, \& reynar», 5. «... ficando... todos os outros tribunaes como subordenados ao Paço, pelo corpo que faz com S. Magestade em coanto lhe aconselhe o que a justiça, \& conservaçaõ de seu reyno toca», 23.

${ }^{31} \mathrm{La}$ evolución de un entramado paulatinamente complejo, desde su esbozo visigótico puede seguirse en Ernst Mayer, Historia de las Instituciones Sociales y Políticas de España y Portugal durante los siglos $V$ al XIV, II (Madrid: Anuario de Historia del Derecho Español, 1926), 43-115 (reimp. Scientia Verlag Aalen, 1991); Henrique de Gama Barros, História da Administração Pública em Portugal nos Séculos XII a XV, III (Lisboa: Livraria Sá da Costa Editora, 1956), 199-201 y 245-286; Caetano Marcello, Lições de História do Direito Português feitas no curso do $1^{\circ}$ ano da faculdade de Direito, em 1961-1962 (Coimbra: Editora Limitada, 1962), 241-267; "Desembargo do Paço", Dicionário de História de Portugal. Dirigido por Joel Serrão, vol. I (Porto: Livrária Figueirinhas, 1984), 803-804; "Suplicação, Casa de”, op.cit., vol. VI, 103-104; Armando Luis de Carvalho Homem, O Desembargo Régio (1320-1433) (Porto: Instituto Nacional de Investigação Científica-Centro de História da Universidade do Porto, 1990); José Subtil, “A administração central da Coroa", en No alvorecer da Modernidade (1480-1620). Vol. III de la História de Portugal dirigida por José Mattoso coord. Joaquim Romero Magalhaes (Lisboa: Editorial Estampa, 1997), 75-89.

${ }^{32}$ Curto, $A$ cultura política, en op. cit., 111-137. Trata sobre el profundo significado político de la audiencia real en 128-129.

33 Barata, As regencias, 128. Este hecho tenía consecuencias añadidas, dado que «a estruturação de um (tribunal) afectava e implicava a reforma dos outros». 
identificándolo hasta tal punto la literatura política moderna con su persona que sus miembros eran considerados parte del cuerpo místico del propio príncipe ${ }^{34}$. Para una época más avanzada, esta connaturaleza se manifestó en la firma de ciertas resoluciones sin la participación de la persona real, práctica inconcebible para los letrados castellanos implicados en la arquitectura jurídica de la anexión de 1580-81, como el licenciado Rodrigo Vázquez de Arce. Esta condición única y unitaria tuvo una traducción en el uso del espacio palaciego e implicó naturalizar la presencia de Desembargo y Suplicação en su ámbito más doméstico y reservado, apreciable tanto en los códigos que regulaban la circulación y uso del mismo ${ }^{35}$, como en otras disposiciones. A la espera de una recogida sistemática de fuentes primarias in situ, buen indicio de la descrita realidad son las referencias contenidas en fuentes cronísticas más o menos coetáneas y otros trabajos de investigación, de las que pasamos a ocuparnos.

Como afirma Ana Isabel Buescu, «é inegável que ao longo do século XV se assistiu, também em Portugal, ao desenvolvimento e à estruturação de mecanismos por parte da coroa que estiveram na base do progressivo fortalecimento do poder régio a caminho de um Estado moderno, que por várias formas e manifestações os reinados de D. João II (r. 1481-1495) e D. Manuel (r. 1495-1521) haviam de exprimir de forma clara ${ }^{36}$. De tales mecanismos formó parte la implicación regia en el ejercicio jurisdiccional directo, traducido en su presencia en el espacio palaciego. Como señaló Garcia de Resende en su Crónica de D. João II, «... todas las sestas feyras hia sempre a relaçam pollas manhas, e as tardes estava com desembargadores do paço, e os sábados á tarde hya a fazenda, e estava na mesa dela com os vareadores, e escrivães, vendo as causas que relevavam ${ }^{37}$. Como veremos, las fuentes van indicando con paulatina claridad un importante matiz diferencial entre las audiencias del rey con el Desembargo y con la Suplicação, situados ambos, en un principio, fuera de los límites de palacio. Si en el primer caso son sus miembros quienes van al encuentro del rey, presumiblemente en su Cámara, en el segundo es el rey quien se desplaza a la sede de la Casa de Suplicação para presidir su Relação (Audiencia), en lugar de su regedor. No cabe concluir una suerte de subordinación de la Casa de Suplicação respecto a los desembargadores por el hecho de ser el rey quien se desplazase a ella, dado que, en realidad, era su persona la que dictaba la calidad del espacio en el que se movía como tal espacio palaciego, dotado, según las circunstancias, de diferente estabilidad o dimensiones ${ }^{38}$.

34 António Manuel Hespanha, História das Instituções. Épocas medieval e moderna (Coimbra: Almedina, 1982), 357-366 (páginas dedicadas al Desembargo do Paço). Las obras de este autor son esenciales para conocer los fundamentos filosóficos del referido sistema político-administrativo.

${ }^{35}$ Cfr., para una época más adelantada, Curto, "Ritos e cerimonias..", A memória da nação. Conviene añadir que, según se aprecia en las fuentes utilizadas, no fueron los únicos órganos administrativos acogidos en tan reservado espacio.

${ }^{36}$ Buescu, D. João III, 184.

37 Chrónica dos valerosos, e insignes feitos del Rey Dom Ioam II de gloriossa memoria, em que se refere sua vida, suas virtudes, seu magnanimo esforço, excellentes costumes, e seu christianissimo zelo, por Garcia de Resende... Coimbra: Na Real Officina da Universidade, Anno de MDCCLXXXXVIII, XVI.

${ }^{38}$ Hablando estrictamente, disociar la Cámara de la propia persona real implica un error, porque, aparte de los bienes muebles e inmuebles que poseía, estaba conceptualmente asociada a la persona real, emanaba de él. De hecho, si se hiciese abstracción de su significado metafórico, la ausencia real 
En tiempo de D. Manuel I tales prácticas jurisdiccionales se consolidaron. Como señaló Damião de Gois:

Todas las sestas feiras do anno... hia sempre a casa de supplicação ouvir os presos, \& ser presente ao dar as sentenças, \& isto sem nunca faltar, nem lho nenhum outro caso impedir, senam doença. Nas mesmas sestas feiras depois de comer despachava ordinariamente com os desembargadores do paço todalas cousas q tocavam a seus officios, sem lhes ficar nenhuma petição por despachar ${ }^{39}$.

Conviene aclarar que por entonces el Desembargo carecía de la consistencia institucional con la que posteriormente sería reconocido. Para esa altura hay que hablar antes de desembargadores do paço, integrados en la Casa de Suplicação, el tribunal supremo del reino ${ }^{40}$. La tendencia hacia la institucionalización del Desembargo cobró forma durante el reinado de D. Manuel, y se debió con toda seguridad a la continuidad de la presencia semanal de los desembargadores en el espacio doméstico del rey. De hecho, D. Manuel reservó espacio en su testamento para disponer la presencia del organismo en Palacio: «Item pera com mais certidam serem despachados e expedidos os negocios, encomendamos que no Paço haja casa ordenada, em que se ajuntem os deputados, pera entenderem em todos os negocios... ${ }^{41}$. No sorprende, por lo tanto, que en lo relativo al Desembargo el reinado de Dom João III consistiese fundamentalmente en hacer material el deseo testamentario de su padre. Con todo, la disposición de sala propia en palacio -la en adelante denominada Casinha- no homologó el procedimiento de la consulta mantenida por el rey con el Desembargo, con la practicada con la Casa de Suplicação. En opinión de Ana Isabel Buescu, en ella se preparaban los casos de orden administrativo y judicial (elección y provisión de oficios, confirmación de cargos municipales, autorización de mayorazgos y capillas, legitimaciones, privilegios, etc.), que posteriormente los desembargadores presentaban al rey en su Cámara para ser sometidos a su despacho ${ }^{42}$.

En una crónica posterior a su muerte, Francisco de Andrada mencionó la entrada de D. João III en la Relação para subrayar las cualidades del difunto como rey clemente y justo $^{43}$, como también hizo -en testimonio física y cronológicamente más

vulgarizaba las dependencias usualmente utilizadas por el monarca como tal Cámara, hecho que obligó a desarrollar mecanismos de significación simbólica.

${ }^{39}$ Chrónica do felicissimo Rey Dom Emanuel de gloriosa memoria. A qual por mandado do Serenissimo Príncipe, o Infante Dom Henrique seu filho, o Cardeal de Portugal, do título dos santos quatro coroados, Damião de Gois coligio, $e$ compos de novo. El Rey N. Senhor a mandou ver por seu coronista mor Ioão Baptista Lavanha \& está conforme a que o Autor acima mandou imprimir. Ao Excelso S. D. Theodosio Duque de Bragança, etc. Anno 1619. Con todas as licenças e aprovações necessarias. Em Lisboa por Antonio Alvarez impressor, y mercador de livros, e feita a sua costa, f. 342r.

${ }^{40}$ Sus competencias, en Barata, As regencias, 128-130.

41 D. António Caetano de Sousa, Provas da História Genealógica da Casa Real Portuguesa. Nova edição revista por M. Lopes de Almeida e César Regado (Atlántida-Livraria Editora, 1947), 430.

${ }^{42}$ Buescu, D. João III, 190.

43 «Foi de natureza branda \& benigna, as sentenças de morte nunca quis que se concluiram senão com muyto vagar, \& depois de hum largo exame. Nunca mostrou muyto bom rosto aos julgadores que sabia q erão rigorosos. Quando se achava presente na Rolação aos despachos della, que era huma vez 
alejado- Saavedra Fajardo ${ }^{44}$. En lo que toca a la presencia de los desembargadores en la Cámara Real, sabemos por los Ditos portugueses dignos de memória que tenía entonces carta de naturaleza ${ }^{45}$, y que las audiencias mantenidas por ellos en ese ámbito eran aprovechadas también por el rey para plantearles solicitudes de merced recibidas de su propio servicio doméstico, legalmente formalizadas ${ }^{46}$. También se dedujo indirectamente del argumento aportado por Francisco de Monzón para defender la presencia cotidiana de la música en Palacio, tener el rey «deputados muy singulares músicos que con delicados instrumentos y muy singulares vozes tañen y cantan mientras su alteza está en siesta: y entonces tiene por costumbre de despachar y oyr las personas más graves y entender en las cosas que más cumplen a la governación de reynos y señoríos ${ }^{47}$. Esta serie de testimonios permiten presumir que para el momento de la muerte de D. João III la audiencia jurisdiccional del monarca con Desembargo y Suplicação era una práctica administrativa convertida ya en hábito.

\subsection{Sebastião (1557-1578). Regencias y disputa política. La suspensión de facto de la audiencia jurisdiccional del rey}

La tendencia hacia la institucionalización del Desembargo continuó durante el reinado de D. Sebastião, incluidas las regencias de la reina doña Catalina (1557-1562) y del Cardenal D. Henrique (1562-1568). La minoridad del rey y las disputas faccionales asociadas no fueron obstáculo para ello, antes al contrario, las tensiones de orden político que entonces tuvieron lugar propiciaron la publicación de repetidas y

cada somana, mais inclinado se mostrava ha brandura da equidade, que ao rigor de justiça...», Crónica do muy alto e muito poderoso rey destes reynos de Portugal dom João o III deste nome. Dirigida ha C.R.M. del Rey dom Felipe o III deste nome nosso senhor. Composta por Francisco d'Andrada do seu Conselho, \& seu Cronista Mor, Anno 1613... Impresa em Lisboa com as licenças necessarias por Iorge Rodríguez, Quarta Parte, f. 154v. El autor continuaba refiriendo cómo suprimió una ley que imponía señales físicas a los ladrones.

44 Para ello, mencionaba ejemplos del contexto portugués: «Asistiendo el Rey de Portugal Don Iuán el Tercero a la vista de un proceso criminal, fueron iguales los votos, unos absolvían al reo, otros le condenavan, y aviendo de dar el suyo, dijo: los que le avéis condenado, avéis hecho justicia, a mi entender, i quisiera, que con ellos se uviesen conformado los demás. Pero yo voto que sea absuelto: porque nos e diga, qu epor el voto del Rei fue condenado a muerte un vasallo», Idea de un príncipe político christiano, representado en cien empresas, dedicada al Príncipe de las Españas nuestro señor por Don Diego de Saavedra Faxardo..., Amberes: En casa de Ierónymo y Iuan Bapt. Verdussen, 1655, 444.

45 Ditos portugueses dignos de memória. História intima do século XVI anotada e comentada por José H. Saraiva, $3^{\mathrm{a}}$ ed., Mem Martins: Publicações Europa-América, Lda., no 758 (281): «Estando o camareiro-mor no Paço falando com certos desembargadores do Paço, que estavam para falar a el-rei...».

${ }^{46}$ Op. cit., $\mathrm{n}^{\circ} 91$ (48), «Desejando el-rei fazer mercê a um criado seu de muito serviço de um oficio que lhe pediu, mandoúlhe que le fizesse disso petição, por ser negócio que havía mister de ser comunicado com letrado. E, depois que o criado lhe-trouxe a petição, tomou-lhe e, estando em despacho com desembargadores do Paço, mostrou aquela petição a um deles e perguntou-lhe se podia faze aquilo...». La respuesta fue negativa (hecho que habla de la igualdad de rey y Desembargo en el ejercicio de la jurisdicción), pero tiempo después el rey se desquitaría en coyuntura semejante con el desembargador que le había negado la petición.

${ }^{47}$ Libro primero d'l Espejo del príncipe christiano que trata cómo se ha d'criar un príncepe o niño generoso desde su tierna niñez con todos los exercicios \& virtudes que le convienen hasta ser varón perfecto... por Francisco de Monçon. Lisboa: en... casa de Luis Rodríguez 28 Iulio 1544, f. CXXVIIIv. 
detalladas disposiciones que tendían a mantener una institución de creciente importancia y poder a distancia de la ambición de los regentes, especialmente la reina doña Catalina y su actitud pro-hispana. Con ello, la coyuntura no fue favorable para el mantenimiento de las audiencias del rey con Desembargo y Suplicação, empezando por la propia minoría del rey, situación que se mantuvo una vez que alcanzó el uso efectivo de la autoridad.

Conforme a ello, el 20 de octubre de 1557 fue publicado un alvará que extendía la potestad de los desembargadores para conceder perdones sin la aprobación del rey. Otro alvará de 11 de mayo de 1562 publicaba el Regimento da Casa do despacho dos desembargadores do paço, conjunto de medidas que sistematizó su funcionamiento. No sólo pasó a ser un tribunal de funcionamiento diario, con un tiempo de despacho pautado a lo largo de la semana en el que tenía cabida la atención particular a los asuntos de las diferentes comarcas. Las sextas-feiras se reservaban para la tramitación de las peticiones ya presentadas, «E no mesmo dia a tarde virão todos aa dicta casa do despacho e não os mandando eu chamar para com elles staar emdespacho despacharão as petições e cousas outras q tiverem para despachan». Si se analiza con atención, conforme está redactada esta disposición tiene gran importancia, pues quedaba convertida en potestad regia la opción de llamar o no a los desembargadores a su Cámara, que en los reinados anteriores debió ser frecuentemente aplicada de facto. El hecho de que en caso de no ser llamados retomasen el despacho de peticiones, esto es, aquello que habían estado haciendo toda la mañana, permite aventurar que la cláusula salvaba formalmente la posibilidad de la audiencia conjunta, pero que de hecho se propiciaba su suspensión ante la falta de rey capacitado y el deseo de no conferir tan poderosa herramienta a la regente ${ }^{48}$.

Con la asunción de la regencia por Dom Henrique (23 de diciembre de 1562) vio la luz un nuevo regimento para el Desembargo, culminado con dos puntos de gran importancia. Uno primero que subrayaba su identificación y unicidad con la persona real, como era la prescripción del formulario de las provisiones a despachar por el tribunal, dado que comenzarían por la intitulación del rey, D. Sebastião, y otro que priorizaba la referida manifestación espacial del gobierno doméstico regio. Puesto que llamaba a atender en primer lugar a las cartas de oficiales de justicia «e de outras pessoas, que andão e servem S.A. pelo regno, e das cámaras das villas e lugares delle» ${ }^{49}$. En cuanto al acceso de desembargadores a la Cámara Real en tiempo de la regencia del Cardenal Dom Henrique, es de creer que continuó vigente la señalada disposición. En

\footnotetext{
48 Esta reglamentación en Arquivos Nacionais Torre do Tombo (ANTT), ms. 870, ff. 77r.-78v., alvará elaborado por Fernão da Costa, en Lisboa, el 11 de mayo de 1562, apud Maria Barata, As regencias, 104-106.

${ }^{49}$ En este sentido, tales provisiones finalizarían con un escatocolo que mencionaba también al rey, «El Rei nosso senhor o mandou por foão e foão», tomado del regimento del chanceler-mor, op. cit., 110. A la cuestión de la intitulación real también se refiere Jorge Veiga Testos, "O chanceler da Casa de Suplicação e o controlo dos actos dos desembargadores", en Control y responsabilidad de los jueces (Siglos XVI-XXI) , coord. José Sánchez-Arcilla Bernal (Madrid: Editorial Dykinson, 2017): 83-97 y 92.
} 
la Carta de D. Álvaro de Castro ao Cardeal D. Henrique sobre o governo do reyno ${ }^{50}$, propia de una situación de inestabilidad política como la regencia, que en línea con lo expuesto reivindicaba como fundamento principal del sistema político la justicia, se lee: «Espero que V. A. proveja nisto, como entendo que começa a fazer, visitando as Relaçõens cada semana $\rangle^{51}$. Pese al claro objeto de la misiva, nada se decía en ella del despacho con los desembargadores, pero implícitamente se percibía la continuidad de la importancia conferida al ejercicio de la justicia directa en audiencia por parte de las personas reales.

Las disputas políticas que acompañaron al periodo de regencias se aprecian asimismo con toda claridad en otro importante aspecto que afectó por entonces al Desembargo, la propuesta de designación de presidente, que ofrecía, dada la peculiar identificación de la institución con la persona real, profundas repercusiones de orden doctrinal. Inicialmente, la prioridad de mantener a doña Catalina al margen de instrumento tan poderoso como la entrada en audiencia con los desembargadores condujo al poco del inicio de su regencia al arzobispo de Braga a proponerle la designación de presidente para el tribunal. A su vez, las Cortes de Lisboa de 1562 solicitaron la provisión de tal figura tanto para la Mesa da Consciência, como para el Desembargo ${ }^{52}$, y en 1564 fue propuesto para el cargo dom João de Melo, arzobispo de Évora, quien ejercía como desembargador do paço e petiçóes desde el 2 de agosto de $1561^{53}$. El personaje carecía de neutralidad política, puesto que había sido capellán mayor de la princesa doña Juana, madre de don Sebastián, y con su designación para la plaza se insinuaba su ejercicio como nexo de relación entre la poderosa señora y el regente.

Conocida la decisión, la conciencia sobre la íntima conjunción de la institución con la persona real asomó en la teatral reacción de uno de sus miembros, Baltasar de Faria, quien «animozamente se levantou do despacho dizendo, que não serviría de ministro em Tribunal com Prezidente donde só as Magestades o tinhão sido», como dio noticia Pinto Ribeiro, recogió Coelho Veloso y ha transcrito Themudo Barata ${ }^{54}$. La

${ }^{50}$ Cuyo título invita a fechar en la época de la regencia, antes que en la de Dom Henrique como rey, dado que omite cualquier mención a tal condición por su parte.

${ }^{51}$ La carta se encuentra en Filozofia de príncipes apanhada das obras de nossos portuguezes por Bento Joze de Souza Farinha... Tomo II, Lisboa, na officina de Antonio Gomes, MDCCLXXXIX, 1-8: «O fundamento sobre que o Reyno se ha de fundar he a justiça; onde a houver nam a que temer, e aonde a nam facilmente se pode esperar a ruina, e perdiçam do dito reyno. Publicamente se queixam em Portugal que a nam ha, e deve ser bastante prova ver os morgados, que os officiaes de justiça adquirem, e deixam, devendo-se elles apenas poder manter. $\mathrm{O}$ remedio para isto facilmente o darey naquellas palavras que V. A. Já ouviria que disse Vasco Fernández César, que sam fazer bem aos bons, e castigar os ruins», 5. Entre otros pasajes representativos del clima de creciente escepticismo sobre la fortuna política del reino que cundía entre las elites portuguesas: «Quem com prudencia zonsiderar o estado do mundo, e corrupçam de Portugal em todo o genero de couza, veraá claro quam necessario seja plantar novo reyno, novos homens, novas leys, novas costumes...», 4.

52 "Apontamentos dos prelados sobre as cousas que se devem tratar e assentar em estas Cortes, e assi outras lembranças geraes e particulares que lhes pareceo que se devião fazer a El Rei nosso senhor pra boa governança destos reynos", Lisboa, 17 de febrero de 1563, en Reflexões históricas pelo conselbeiro João Pedro Ribeiro, Parte II (Coimbra: na imprensa da Universidade: 1836), 95-124, 100.

53 Marcelo Caetano, "Desembargo do Paço", Verbo. Enciclopédia Luso-Brasileira de Cultura, 6 (1967), 1095.

${ }^{54}$ Barata, As regencias, 111 y fuentes ahí citadas. 
inmediatez de la disputa política, dirigida a dificultar al regente el control del poderoso organismo, estaba poniendo en riesgo los fundamentos doctrinales de una jerarquía fundada en la identificación del organismo con la persona real, que explicaba su presencia en el ámbito doméstico regio y en definitiva, permitía la implementación del gobierno basado en su ampliación. En este sentido, es elocuente la identidad de otro de los oficiales regios opuestos a la medida, Pero de Alcaçova Carneiro, el famoso secretario de Estado que por entonces acumulaba interinamente las funciones de escrivão da Puridade, cargo que desde su origen se distinguió por su estrecha relación con el espacio doméstico reservado de la Cámara. Themudo Barata señala que la razón de esta postura pudo ser su propia apetencia por el cargo, pero, dados los oficios que compatibilizaba, no hay que descartar que esa posición se debiera a una legítima preocupación por las consecuencias que la medida pudiera tener sobre el propio sistema de gobierno y la posición del Desembargo do Paço en él. La resistencia originada condujo a D. Henrique a cancelar la propuesta, por alvará de 30 de octubre de 1564 que, según Aragão Morato, aludía como motivo para hacerlo a la oposición de Alcaçova Carneiro y le confería la última palabra al respecto, caso de retomar la propuesta $^{55}$.

La posición del Desembargo continuó siendo fortalecida con nuevas disposiciones reglamentarias con el acceso de Dom Sebastião al pleno ejercicio de sus facultades reales. Tan solo siete meses después, aparecía un nuevo regimento que extendía las atribuciones del tribunal (20 de julio de 1568). Formaba la ley IV del Título IV en las Leis extravagantes de Nunez de Leão, bajo un expresivo título: «Dos casos que os desembargadores do paço podem despachar além de seu regimento» ${ }^{56}$. Con posterioridad, no parece haber disposiciones de calado relativas al Desembargo durante el resto del reinado de Dom Sebastião. De tal manera que, con toda la prudencia, se puede considerar vigente la disposición que establecía la reunión potestativa del rey con los desembargadores, que los dos últimos regimentos referidos mantenían de forma implícita. No es posible por el momento fijar la proporción en la que D. Sebastião ejerció tal potestad. Es de creer que, hasta su abrupta desaparición en Alcázarquivir en 1578, tal carácter optativo debió ir espaciando las ocasiones en las que el rey mantuvo el contacto directo con el Desembargo, sin que podamos afirmar nada en lo relativo a la Suplicação. Salvo que, en el curso de la jornada que la Grande Peste de Lisboa le obligó a hacer en 1569, aunque fuese acompañado por el Consejo e hiciese justicia personalmente, D. Sebastião decidió salvar a sus súbditos los inconvenientes derivados de una situación que les impedía pedir justicia ante la Casa de Suplicação y ordenó la creación de órganos jurisdiccionales próximos ante los que apelar. En un contexto que

55 Synopsis chronologica de subsidios ainda os mais raros para a hist'ria e estudo crítico da legislação portuqueza: mandada publicar pela Academia Real das Sciencias de Lisboa e ordenada por José Anastasio de Figueiredo. Tomo II, Desde 1550 até 1603 (Lisboa: na officina da mesma Academia. Anno MDCCXC), 101; "Memoria sobre os escrivães da puridade dos reis de Portugal, e do que a este officio pertencia,...", 198-199; Barata, As regencias, $110-112$.

${ }^{56}$ Leis extravagantes collegidas e relatadas pelo licenciado Duarte Nunez de Lião, per mandado do muito alto e muito poderoso rei Dom Sebastião nosso senhor (Coimbra: Na Real Imprensa da Universidade. Anno de MDCCLXXXXVI), ff. 21r.-22r. 
Castilla y Portugal compartían, el ejercicio administrativo, como un hecho objetivo y atemporal, se basaba así en una reproducción itinerante de la Cámara, que daba cohesión al espacio territorial y era incompatible con una dinámica centro-periferia que sólo adquirió naturaleza con la llegada del Estado Liberal ${ }^{57}$.

\subsection{Henrique I (1578-1580). La audiencia jurisdiccional subordinada a la urgencia sucesoria}

La situación abierta como consecuencia de Alcázarquivir tampoco favoreció el ejercicio de las referidas prácticas jurisdiccionales. En la Chrónica do Cardeal Rei D. Henrique, no se contiene referencia a su entrada en la Suplicação, ni a la de los desembargadores do paço en su cámara ${ }^{58}$. La situación del reino, volcada en la resolución del dilema sucesorio y, por lo tanto, propicia para el protagonismo en el espacio doméstico regio del Consejo de Estado y de los secretarios, implicó con toda probabilidad desatender las prácticas jurisdiccionales que venimos refiriendo. Quizá la entrada del Cardenal Rey con el primero referida por Saavedra Fajardo -con el objeto de ilustrar la conveniencia de que el monarca no diese indicio de su criterio a sus consejeros $^{59}$ - fuese regla de conducta. No obstante, este hecho era compatible con la importancia de un organismo, el Desembargo, que ganó importancia en la referida coyuntura, en la que la intervención jurídica de los desembargadores sería continua.

De hecho, la decisión de que Don Henrique fuese proclamado curador, gobernador y sucesor del reino resultó de una reunión encabezada por Simão Gonçãlves Preto, chancerel mor, y los doctores Paulo Afonso, Gaspar de Figueiredo, Hierónimo Pereira de Sá, Pero Barbosa y Manoel de Quadros, desembargadores do paço ${ }^{60}$. Contrástese esta intervención, por ejemplo, con su ausencia en los actos que siguieron a la muerte de D. João III, cuando fueron convocados a Consejo con la reina doña Catalina el Cardenal Infante, el duque de Aveiro, los condes de Castanheira y de Vimioso, el regedor de la Casa de Suplicação, el barón de Alvito, el chancerel mor Gaspar de Carvalho y los vareadores de la ciudad de Lisboa, sin que aparezca referencia en esa

\footnotetext{
${ }^{57}$ Antonio Villacorta Baños-García, Don Sebastián Rey de Portugal (Barcelona: Editorial Ariel, 2001), 112.

${ }^{58}$ Chrónica do Cardeal Rei D. Henrique. Vida de Miguel de moura escripta por elle mesmo. Publicadas com algunas annotações pela Sociedade propagadora dos conhecimentos utéis, Lisboa: 1840.

${ }_{59}$ «El Rey Don Enrique de Portugal fue tan advertido en esto, que proponía los negocios a su Consejo, sin que en las palabras o en el semblante se pudiese conozer su inclinación», Idea de un príncipe politico christiano..., 415-416.

${ }^{60}$ Ante la decisión acordada, aposentado el Cardenal en las casas del Duque de Braganza («por se não atrever com dar a ver os paços onde el rei morava»), convocó a los señores y fidalgos que había en la ciudad, «com os vereadores e mais Câmara, chanceller e desembargadores do paço, a Casa da Supplicação e Cível, com os da mesa da consciencia e mais tribunaes de justiça e officiaes pera fazerem o acto de alevantamento, pera provisão do governo do reino...», Chrónica de El Rei D. Sebastião por Fr. Bernardo da Cruz publicada por A. Herculano, e O Dr. A.C. Payva, (Lisboa: na impressão de Galhardo e irmãos, 1837), 321-322.
} 
coyuntura a la intervención de los desembargadores do paşo ${ }^{61}$. Sin duda, la posición ganada era resultado de una tendencia sostenida de articulación institucional y soporte reglamentario manifestados en los referidos regimentos de 1562, 1564 y 1568. Lo paradójico es que, según hemos visto, las regencias implicaron una suspensión de facto de aquella atribución que manifestaba más rotundamente su identificación con la persona real, la entrada en su Cámara para celebrar audiencia jurisdiccional con ella.

\subsection{Filipe I (1581-1598) hasta el regreso a Castilla en 1583. La recuperación de la audiencia jurisdiccional regia.}

Como señala Pedro Cardim, la inserción de Portugal en la flamante construcción de la monarquía hispana sensibilizó en términos constitucionales a las élites del reino, y su naturaleza y caracteres atrajeron bien estudios teóricos, bien escritos políticos y cortesanos ${ }^{62}$. Pero, en un contexto patrimonial, la nueva situación materializaba también un evento de orden dinástico y patrimonial que, fiado al azar y a las negociaciones matrimoniales, podía haber acontecido en diferentes ocasiones ya desde un siglo antes, y especialmente según avanzaba el reinado de un D. Sebastião remiso al casamiento y, por tanto, sin hijos. Otra cosa fue la larga apuesta diplomática mantenida por Felipe II de Castilla para que esa fuera finalmente la posibilidad triunfante. Así, las relaciones luso-castellanas respondían a dos impulsos, uno tradicional $^{63}$, de raíces medievales, y otro simultáneo, paralelo a la construcción y orientación de la monarquía hispana. En este sentido, se puede afirmar que se dio un procedimiento tradicional para ungir la adhesión de Portugal a la naciente construcción política.

Entre las cuestiones presentes en las dos líneas argumentales destacó la ausencia real. Si por un lado fue uno de los principales motivos de respuesta de las élites portuguesas a la inserción de su reino en la dinámica de la Monarquía Hispana, por otro urgió a la corona a subrayar y vigorizar las formas implícitas y metafóricas de la presencia real, en las que, según lo dicho, destacaba el gobierno doméstico regio extendido desde la Cámara Real al territorio, con intervención directa del propio rey. Llegado al trono luso, Felipe II reformó el paço da Ribeira, no sólo para vivir, sino también para articular su propia integración en tal sistema autóctono de gobierno; sistema que permite comprender el stajanovismo constructivo de Juan de Herrera, en Castilla tanto como en Portugal (implicado en la práctica totalidad de dichas actuaciones arquitectónicas, a causa de su cualidad de aposentador de Palacio, para la que

${ }^{61}$ Ante ellos fueron abiertos unos capítulos que el difunto rey tenía hechos algunos días antes de su muerte, en los que nombraba tutora de el príncipe su nieto a la reina doña Catalina, así como gobernadora de los reinos hasta que el príncipe alcanzase los 20 años (Crónica do muy alto e muito poderoso rey destes reynos de Portugal dom João o III deste nome, f. 154v.).

62 Pedro Cardim, "El estatus político de Portugal en la Monarquía Hispana", en Portugal y la Monarquía Hispánica, (ca. 1550-ca. 1715) (Madrid: Marcial Pons, 2017) 43-77.

${ }^{63}$ Fernando Bouza Álvarez, "De un fin de siglo a otro. Unión de coronas ibéricas entre Don Manuel y Felipe II", en El Tratado de Tordesillas y su época. Congreso Internacional de Historia, III, La ejecución del Tratado y sus consecuencias (Madrid: Sociedad V Centenario del Tratado de Tordesillas, 1995), 1453-1463. 
eran complemento indispensable sus dotes de alarife, y no al contrario $\left.{ }^{64}\right)$. Se apreciaba una profundidad simbólica del espacio en que el rey ejercía su acción de gobierno, como indica el determinado impulso dado por Felipe II, ya como Filipe I de Portugal, al torreón del Paço da Ribeira, conceptualmente relacionado con la Torre Dorada del Alcázar de Madrid. Así, el nuevo aposento se entendió como un cuerpo torreado adosado a un extremo de la fachada del palacio ${ }^{65}$. En ambos casos, eran los apartamentos más recogidos, la Cámara, y su articulación, la que determinaba los usos asociados y complementarios de tal espacio, entre otros, los propios del orden administrativo y jurisdiccional. Además, en el nuevo torreón Don Felipe instaló la biblioteca del palacio así como su sala principal de recepción, la Sala Real, llamada dos embaixadores, de tal manera que, en opinión de Nuno Senos, la organización interna del edificio fue profundamente modificada ${ }^{66}$.

Esta intervención perfiló la apariencia costera de Lisboa desde el mar dà palha anterior al terremoto de 1755 y contuvo, en la referida Sala, alegorías pictóricas tanto de la grandeza monárquica como del beneficio representado para ella por la asimilación del reino portugués. Este intencionado conjunto de significados operó en la construcción, también con la profunda intervención de Herrera, del monasterio de São Vicente de Fora (cuya primera piedra se puso el 25 de agosto de 1582) ${ }^{67}$. Sobre tales fundamentos, a partir del hecho consumado de su alejamiento del reino, la interrupción u olvido de la presencia simbólica del rey en el territorio era un error que la corona no podía permitirse, de manera que se sofisticó su forma más perfecta, la integración espacial de orden oeconómico entre la Cámara Real y el territorio del reino, para adaptarla a la nueva situación, tanto en lo relativo a la alteridad representada por el virrey o gobernador, como a perfeccionar la relación del sistema con el propio rey ausente. De hecho, el discurso político y administrativo portugués desde 1580 derivaba de la presencia o no del rey, y, con eso la importancia del ámbito que contenía su actividad particular y oficial, la Cámara, fue subrayada en un doble sentido físico y metafórico. Si el rey decidiese dejar el reino, la propia naturaleza de su sistema administrativo hacía ver que tal recipiente tendría gran importancia en la articulación del gobierno, precisamente a causa de su propia ausencia.

64 Toco estas cuestiones en Ignacio Ezquerra Revilla, “Aportación al estudio de la Junta de Policía (1590-1601)", en Homenaje a Antonio Dominguez Ortiz, dir. Rafael Vázquez Lesmes (Córdoba: Real Academia, 2004), 259-282, especialmente, 274-277, y las fuentes allí citadas. Sobre la labor de Juan de Herrera en Portugal Jorge Segurado, "Juan de Herrera em Portugal", en As relaçoes artísticas entre Portugal e Espanha na época dos decobrimentos, coord. Pedro Dias, (II Simpósio luso-espanhol de História de Arte) (Coimbra: Livraria Minerva, 1987), 99-111 y Francisco Javier Pizarro Gómez, Arte y espectáculo en los viajes de Felipe II (Madrid: Ediciones Encuentro, 1999), 45-46.

${ }^{65}$ Fernando Chueca Goitia, "El estilo herreriano y la arquitectura portuguesa", en El Escorial 15631963. IV centenario de la fundación del Monasterio de San Lorenzo el Real, 2 (Madrid: Patrimonio Nacional, 1963), 215-262, 224-228; Georg Kubler, Portuguese plain architecture. Between spices and diamonds (1521-1706) (Middletown [Connecticut]: Wesleyan University Press, 1972), 77-79.

${ }^{66}$ Rafael Moreira, "O torreão do Paço da Ribeira", Mundo da Arte 14 (1983): 43-48.

${ }^{67}$ Rodrigo da Cunha, História Eclesiástica da Igreja de Lisboa (Lisboa: 1642), parte 2, cap. 4, par. 7, apud José da Felicidade Alves, O Mosteiro de São Vicente de Fora (Lisboa: Livros Horizonte, 2008), esp. pp. 24-25. 
Esto era todavía más fundamental, si se considera que una base tan tradicional de gobierno podría favorecer indirectamente la valoración por el pueblo portugués de un artefacto político abstracto como la monarquía hispana, promotor dudoso conforme a lo señalado por Cardim- de sentimientos de lealtad y pertenencia ${ }^{68}$. La construcción del espacio cortesano en un sentido administrativo era un polo de cohesión tradicional subsumido en la política de amplio rango impulsada por el concepto de monarquía hispana. En este sentido, cabe afirmar que la anexión fue resultado de una mezcla de factores como el interés y conveniencia de las élites económicas o la operatividad de aspectos tradicionales e históricos de mutua integración, caso de la identidad política y cultural, de la que formaba parte el descrito sistema extendido de gobierno, derivado de la tradición visigoda. La actualidad de la reforma de justicia en ese contexto formaba parte también de ese cuadro.

En el fondo, este juego permitió comprender el proprio ejercicio del gobierno real y las diferencias inherentes a la presencia o ausencia del rey, apreciadas por autores como Cardim, Torres Megiani, Bouza y Labrador ${ }^{69}$. Antes de la eventualidad del abandono del reino por la persona real, era esencial mantener la racionalidad y verosimilitud del funcionamiento nacido de la Cámara, lo que se tradujo en una serie de decisiones, como la mejora del gobierno local del Desembargo o la presencia del gobernador o vice-rei en las consultas de sexta feira de la Suplicação y -probablemente- el despacho con ellos de los desembargadores do paço en su antecámara. Aspecto tan esencial para el mantenimiento del sistema de gobierno integrado y continuo que referimos constaba en el Regimento firmado por Filipe I el 31 de enero de 1583, sujeto a la Carta Patente de la misma fecha por la que nombraba gobernador al Archiduque Alberto. Era un documento que, conforme al señalado sistema político, llamaba a la conservación de la religión y de la justicia ${ }^{70}$, y se esforzaba por mantener una integración administrativa de orden doméstico. Esta quedaba plasmada en la entrada en servicio del gobernador de aquellos miembros de la Casa Real portuguesa no inscritos en el servicio de Filipe I y en la observancia de las normas de servicio

\footnotetext{
${ }^{68}$ Cardim, "El estatus político", 53.

69 Pedro Cardim, “La jornada de Portugal y las Cortes de 1619”, en La Monarquía de Felipe II: los reinos, IV, dirs. José Martínez Millán-María Antonietta Visceglia (Madrid: Fundación Mapfre, 2008): 900-946; Fernando Bouza Álvarez, "Lisboa sozinha, quase viúva: a cidade e a mudanza da Corte no Portugal dos Filipes", Penélope: revista de história e ciências sociais 13 (1994): 71-94; Ana Paula Torres Megiani, O Rei Ausente: festa e cultura politica nas visitas dos Filipes a Portugal (1581 e 1619) (São Paulo: Alameda Casa Editorial, 2004): Félix Labrador Arroyo, La Casa Real de Portugal (1580-1621) (Madrid: Polifemo, 2009): 319-337.

70 «Tambem vos encomendo quanto he razão a justiça pera que se faça a todos igualmente e haja tanta enteireza e brevidade na administração e execução della como convem ao bem de tudo, e tereis particular lembrança de faser cumprir e guardar as leis, que agora novamente fiz da reformaçam da justiça que são tam importantes e necessarias como por ellas tendes visto», Regimento que o senhor rei Dom Phelippe o $1^{\circ}$ deu ao cardeal Archeduque Alberto pera depois de sua absencia governar estes reinos e senhorios de Portugal, Biblioteca de Ajuda, 50-V-28, ff. 20r-23v., publicado en Filipe II de Espanha, rei de Portugal (Colectânea de documentos filipinos guardados em Arquivos Portugueses. Estudo introdutório e coordenação de Francisco Ribeiro da Silva, vol. I (Zamora: Fundación Rei Afonso Henriques, 2000), 118-122, 118. La Carta Patente con la designación, 123.
} 
tradicionales en ella ${ }^{71}$. Así como en la presencia de Miguel de Moura, escrivão da puridade, en la Junta que -junto con el arzobispo de Lisboa Dom Jorge de Almeida y el vedor da fazenda Pedro de Alcaçova Carneiro- debía de asesorarle permanentemente en todos los asuntos del gobierno, o en la designación del Doctor Paulo Afonso, desembargador do paço, como sustituto de cualquiera de sus tres miembros.

Pero lo destacable del Regimento, conforme con nuestra línea argumental, es que reservaba un lugar destacado a la intervención directa del gobernador, el Archiduque Alberto, en los órganos colegiados de gobierno, obligándole a mantener las mismas pautas practicadas por Filipe $\mathrm{I}^{72}$. En este sentido, durante su permanencia en Portugal -y una vez engranado el sistema de gobierno- el rey se preocupó por mostrar un escrupuloso cumplimiento de las prácticas jurisdiccionales a las que venimos refiriéndonos, para ganarse a sus nuevos súbditos con la observancia de las costumbres vernáculas, pero también con la mira en el momento de su obligada partida. En consecuencia, paradójicamente, el documento que legalizaba la delegación del gobierno contuvo la enunciación más sistemática y detallada de tales prácticas realizada hasta ese momento. Al margen de la señalada junta selecta, el Consejo de Estado se tendría todas las segundas feiras por la tarde, «na forma, ordem e modo que agora por meu mando nellas se tem». Y se añadía:

Com os tribunais da justiça, consciencia e fazenda tereis a mesma ordem que se agora costuma convem a saber: as $3^{\mathrm{a}} \mathrm{s}$ feiras chamareis os vedores da fazenda e officiaes della e as $4^{a}$ s feiras os deputados da mesa da consciencia e as sestas feiras os dezembargadores do paço e ireis a relação hua vez cada mez a sesta feira pela manha, que he o dia em que os senhores reys meus antecessores o costumavão fazer ${ }^{73}$.

Este último punto permite apreciar el grado en que la práctica jurisdiccional portuguesa se vio afectada por la inestabilidad política, dado que, como hemos apreciado a lo largo de nuestro recorrido, esa entrada regia en la Relação había sido semanal, por lo menos hasta el reinado de D. Sebastião. El mayor espaciamiento de tal entrada, y la necesidad de recuperar la conjunción de la persona real con el Desembargo y la Suplicação era un punto ya expresado por el licenciado Rodrigo Vázquez de Arce en el memorial sobre la situación de la justicia portuguesa, firmado en agosto de 1581, que, al incluir aspectos practicados por Filipe I y contenidos en el Regimento dejado por él al Cardenal Alberto revela su valor no sólo como modelo para la reforma judicial portuguesa, sino como pauta de conducta jurisdiccional que el rey prudente no dudó en seguir. En el citado memorial del letrado castellano se lee:

\footnotetext{
71 "As entradas que en nossa casa hão de ter os officiais que nella vos hão de servir e os fidalgos, que a ella vierem, sera conforme ao que antigamente se costumava na casa real de que vos conformareis", 120.

${ }^{72}$ Esta decisión debió implicar escasa novedad para el Archiduque, quien asistió en el gobierno a Felipe II mientras permaneció en Portugal, Francisco Caeiro, O Arquiduque Alberto de Austria. Vice-Rei de Portugal, (Lisboa: 1961), capítulos II y III.

${ }^{73}$ Ambos puntos, en Filipe II de Espanha, rei de Portugal, 119.
} 
Ya que no se use como en otros tiempos asistir los reyes deste reyno con los ministros de justi [ci]a los biernes de cada semana que le daba grande autoridad todavía se la daría permitir V. Md. que le consultasen una o dos vezes cada mes ordenándoles lo que podrían tratar en cada consulta y el tiempo que se podrían detener... ${ }^{74}$.

Vázquez de Arce abundaba en la misma línea poco tiempo después, al defender la conveniencia de

... asistir los reyes con los desembargadores do Paço las sextas ferias de cada semana... q. hacía muchos años q. no se usaba tan ordinariamente y q. si se continuaua haciéndolo algunos días... daría mucha autoridad a la justicia, y el gobernador como menos ocupado podría asistir a las dichas sextas ferias... ${ }^{75}$

aspecto que, como hemos apreciado, fue explícitamente contenido en el regimento dado al gobernador.

Entre otros factores, el despacho del Archiduque con los diferentes consejos y tribunales demostró en opinión de António Manuel Hespanha cómo el desembarco institucional de Felipe II en Portugal pasó, en primer lugar, por un refuerzo de la administración sinodal y jurisdiccionalista, respetuosa con la naturaleza «tópica y argumentativa» del proceso jurídico de decisión. Si el virrey era el alter ego real, lo era a todos los efectos, incluido el ejercicio jurisdiccional que Felipe II no podría realizar en adelante por razones materiales. Consecuentemente, el procedimiento de consulta, a cargo de letrados con la «tecnología administrativa» adecuada, fue el procedimiento mantenido pese a la ausencia real: «Ouvir os tribunais e conformar-se com as consultas era o modelo do bom governo» ${ }^{76}$. El ejercicio de práctica tan apegada a la aureola mítica de la corona como el gobierno y la justicia sin mediaciones se insinuaba como uno de los «padrôes modelares de administração» que, a priori, deberían desembocar en la aceptación y aprecio de la nueva dinastía ${ }^{77}$. Que tal era la prioridad regia puede deducirse del hecho de que el procedimiento de la consulta aparecía descrito en el Regimento que marca la actuación del gobernador, pero no en las nuevas ordenanzas dadas el 27 de julio de 1582 a los organismos jurisdiccionales.

\footnotetext{
74 Me ocupé de este importante memorial, contenido en Archivo General de Simancas (AGS). Estado (E), leg. 408, no 275 en Ignacio Ezquerra Revilla, "Planteamiento de la reforma judicial portuguesa en el contexto de la anexión (1580-1581)”, en José Martínez Millán-Maria Paula Marçal Lourenço, coords., Las relaciones discretas entre las Monarquias Hispana y Portuguesa: las casas de las reinas (Siglos XV-XIX) (Madrid: Ediciones Polifemo, 2008), 2151-2199. Este punto transcrito en 2196.

75 AGS. E, leg. 428. Otra copia em AGS, E, leg. 424, cit. por Diogo Ramada Curto, “A cultura política", 128.

76 António Manuel Hespanha, “O governo dos Áustria e a 'modernização' da constituição política portuguesa”, Penélope. Fazer e desfazer história 2 (1989): 50-73, 58 y 59.

${ }^{77}$ José Hermano Saraiva, História concisa de Portugal (Mira Sintra, 1978) 427.
} 


\subsubsection{Los desembargadores do paço en el Consejo de Portugal.}

No obstante, no todos los desembargadores do paşo podrían asistir en adelante a tales audiencias con el gobernador, como es de presumir que sí hicieron con Filipe I, dado que dos de ellos pasaron a incorporarse en el flamante Consejo de Portugal en Madrid, en decisión dirigida a paliar, en la medida de lo posible, las interferencias que la ausencia real podía causar en el sistema de gobierno doméstico regio extendido. Con esta medida, se daba una especie de relación de orden umbilical -por así denominarloentre el espacio palaciego del rey ausente y el espacio doméstico compartido en Lisboa entre sus compañeros y el gobernador.

Nuevamente, el contenido del regimento permite deducir la preocupación de Felipe II por mantener la operatividad gubernativa de tal espacio, pese a la ausencia de su polo carismático, representado por él mismo. El documento ordenaba al governador dar audiencia general todas las terças y quintas feiras, con servicio de officiais de cana portugueses, y permitir el acceso a su persona cuando se desplazara a misa. Aparte, los fidalgos y consejeros de Estado debían ser oídos en las siestas y en otros momentos en los que no estuviese ocupado ${ }^{78}$. La audiencia era concebida como el momento de presentación de peticiones a la persona real y de inicio de un procedimiento administrativo complicado por la ausencia real, pero que se desarrollaba, pese a su recorrido de más de 600 kilómetros, superior en el caso de jornada real hacia el este (como sucedió, por ejemplo, en 1585 y 1592), en un ámbito netamente doméstico y de vocación continuo. Tales peticiones debían ser entregadas por el propio gobernador a un escribano de Cámara, que las encaminaría a los ministros a quien tocasen. El primero, sin mediaciones, remitiría los requerimentos de filhamentos al Mordomo Mor o, en su ausencia, al vedor, y las solicitudes de presentación del padroado da coroa al obispo deán de la Capilla Real, quien también recibiría las de beneficios de las Órdenes Militares, pero en su calidad de diputado de la Mesa da Consciencia e Ordens.

Seguidamente comenzaba la fase resolutoria, en la que tales ministros harían relación de las solicitudes recibidas, sometidas al criterio del gobernador y de los tres miembros señalados de la Junta. A ellos correspondería elaborar una propuesta de provisión que sería, finalmente, enviada al rey, como también lo sería la relación previa. A este esquema escapaban ciertas provisiones, como las correspondientes a juízes de fora y oficios municipales, siempre que no fuesen de Évora, Coimbra, Porto y Santarém, que podrían ser provistos a propuesta de los desembargadores do paço directamente por el gobernador y la señalada Junta, en presencia del desembargador más antiguo. Se apreciaba, así, la participación de estos ministros en un sistema de gobierno doméstico regio

78 «Todas as $3^{\text {a }}$ s e $5^{\text {a }}$ s feiras pelas menhãos dareis audiencia geral a todas as pessoas, que vos quizerem fallar, os quaes ouvireis assentado e estrão na casa os officiaes portuguezes, de que vos haveis de servir,... especialmente os de cana... Pera que haja outros tempos em que também possão todos chegar a fallar vos e as audiencias dos dous dias de casa semana, de que vos trato no capitulo acima se facilitem mais, ireis a missa a capella todos os dias ou mais que poder ser e alguns dias santos ireis ouvir missa aos mosteiros e igrejas da cidade, hora a uns hora a outros, assi como eu o fazia. Nestas audiencias ordinarias se não entendem as que deveis dar aos fidalgos os quaes ouvireis em pee pela sesta e em outros tempos em que não estiverdes occupado...», Filipe II de Espanha, rei de Portugal, 120. 
extendido que trataba de adaptarse a las disfunciones motivadas por la ausencia real. Su relevante intervención se apreció asimismo en otro punto, la inspección de los perdones reservados al gobernador, que debía firmar en presencia de los tres miembros de la Junta y con el acuerdo del Doctor Paulo Afonso, desembargador do paço ${ }^{79}$. La ligereza en la expedición de perdones por parte de los desembargadores sin intervención real -punto referido ya por el licenciado Rodrigo Vázquez- fue parcialmente atendido en el regimento, que confería esta atribución al gobernador. Con todo, la creación del Consejo de Portugal introdujo un eslabón adicional de intermediación en la cadena decisoria encabezada por el rey en Madrid, legalmente formalizada con las instrucciones para el Consejo y su secretario de 27 de abril de $1586^{80}$.

Pero la presencia y significación de los desembargadores do paço también se dejaba sentir en el espacio propio del rey ausente. De forma unánime, los tres estados habían pedido en las Cortes de Thomar la confirmación de las promesas realizadas en su día por el Duque de Osuna, de las que formaba parte la creación de un Consejo de Portugal que se constituiría junto a la persona real, cuando esta abandonase Portugal. La Carta Patente de 12 de noviembre de 1582, que confirmaba las gracias y peticiones concedidas, contenía la creación de tal Consejo, del que, de forma elocuente, formarían parte dos desembargadores do paço:

Que estando el Rei, ou seus sucesores ausentes do reino, em qualquer parte, trairam sempre consigo um prelado, ou pessoa eclesiástica, um vedor da fazenda, um secretário, um Chacarel Mor, e dois Desembargadores do Paço, naturaes do país, os quaes se intitulariam Conselho de Portugal, e que por elles e com elles despachariam todos os negoceos do Reino. Que da mesma forma estariam sempre, onde residiese a Corte dois escrivães da fazenda e dois de Câmara para exercerem seus oficios, sendo todos os diplomas escriptos em lingua portuguesa. Finalmente, que vindo Sua Magestade, ou seus succesores a Portugal, este Conselho e os escrivães o acompanhariam para servirem com elle alem dos outros oficiaes ${ }^{81}$.

79 «E também aasinareis o Livro da Ementa da chancelaria e os passes dos perdões para se dar nreve despacho as partes tendo muita advrtencia nelles, que se não venha por esta via tirar a justiça a força que tanto convem que tenha, e a dita ementa assinareis quando estiverdes com as 3 pessoas, que neste regimento vos nomeo, para todos os negocios e antes de pordes os passes nos perdões mandareis ao doutor Paulo Afonso que os veja, e vos faça relação em segredo, do que nelles acha para não passarem os em que houver duvida...», Filipe II de Espanba, rei de Portugal, 122.

${ }^{80}$ José Antonio Escudero, La creación del Consejo de Portugal, Separata do número especial do Boletim da faculdade de Direito de Coimbra. Estudos em Homenagem aos Profs. Manuel Paulo Merêa e Guilherme Braga da Cruz, s.a., 18 .

81 Santiago de Luxán Meléndez, La Revolución de 1640 en Portugal: sus fundamentos sociales y sus caracteres nacionales. El Consejo de Portugal, 1580-1640, Tesis Doctoral presentada en la Universidad Complutense en el año 1986, bajo la dirección de Jose María Jover Zamora, 52-53 y 57, notas 47 y 48, con transcripción del texto copiado, y fuentes que contienen las gracias concedidas. Una redacción aproximada, en Antonio de Herrera, Cinco libros de la bistoria de Portugal y conquista de las islas de los Açores, en los años 1582 y 1583..., Madrid: en casa Pedro Madrigal, Año de 1591, Libro Tercero, f. 148r. A la concesión de esta merced también se refirió Luis Cabrera de Córdoba, Historia de Felipe II, Rey de España, II (Salamanca: Junta de Castilla y León, 1998), 961 (ed. a cargo de José Martínez Millán y Carlos Javier de Carlos Morales). El proceso y contexto, en Fernando Bouza Álvarez, Portugal en la monarquía hispánica 
La redacción permitía apreciar la importancia concedida a la cohesión y unicidad de tal forma de gobierno de matriz doméstica, patente en la presencia de ministros y oficiales relacionados con ese ámbito: desembargadores do paço, chancerel mor y escrivães de Câmara. No parece injustificado decir que, con tal decisión, se trataba de crear un hilo coherente de relación en el entramado doméstico luso, entre la porción que permanecía en Portugal, y un rey ausente, pero del que emanaba la racionalidad del sistema de gobierno doméstico regio extendido, según lo estipulado en el estatuto de Thomar. Conforme a ello, no se apreciaban diferencias formales o estatutarias entre los desembargadores do paço que permanecían en Portugal y aquellos que residían junto a Felipe II, y todos ellos eran considerados miembros de un único cuerpo. Su retribución corría por una misma vía, al margen de dónde ejerciesen. Así, la carta de ordenado de Rui de Matos Noronha, desembargador do paço en el Consejo de Portugal, firmada en Madrid el 22 de septiembre de 1583, permite saber que percibían una cantidad de 200.000 reis de ordenado. En ella se mandaba al regedor de la Casa da Suplicação «que o faça yr a Roll com os ditos duzentos mil r[ei]s de ordenado com os ordenados dos outros desembargadores do Paço para elle aver de ser pagos aos quarteis do anno asy como son pagados os assinados dos ditos desembargadores do Paço que actualmente tienen oficio.... ${ }^{82}$. A esta cantidad se añadían otros 100.000 reis como complemento ${ }^{83}$. En el caso de aquellos desembargadores que, como Rui de Matos, permanecían junto al rey, se añadían otros 200.000 reis en concepto de ayuda de costa, asignación considerada una costumbre asentada en una consulta del Consejo de Portugal de 9 de julio de $1598^{84}$.

Los primeros desembargadores do paço nombrados en el Consejo de Portugal fueron el mencionado Rui de Matos Noronha y Pedro Barbosa, cuyos perfiles ilustran la importancia que Felipe II concedió a las plazas que ocuparon. De honda tradición jurídica, el primero de ellos fue próximo a la reina doña Catalina en la Corte portuguesa, lo que le distanció del cardenal don Enrique. Desde su cargo de Corregedor da Corte, en la cuestión sucesoria se mostró proclive a Felipe II, en lo que pudo influir la carrera desarrollada en la Inquisición hispana por su hermano Antonio de Matos Noronha. Fallecido en 1588, su plaza quedó vacante hasta que fue cubierta en 1593 por Jorge Cabedo de Vasconcelos. El caso de Barbosa, profesor de Coimbra y reputado jurista, demuestra cómo la valía personal y el apoyo de un patrón como Cristóbal de Moura podían compensar una elección política errónea, puesto que se había mostrado

(1580-1640). Felipe II, las Cortes de Tomary la génesis del Portugal católico, I (Madrid: Universidad Complutense, 1987).

82 ANTT, Chancelaria de Filipe I, liv. 7, f. 213, transcrito por Santiago de Luxán, La Revolución de 1640 en Portugal, 632.

${ }^{83}$ En Biblioteca Nacional de Lisboa (BNL). Cod. 11543, "Repertório do $1^{\circ}, 2^{\circ}, 3^{\circ}$ e $4^{\circ}$ livro dos assentos do Dezembargo do Paço, com o repertório do $1^{\circ}$ livro de consultas, e hum extracto dos Ordenados e propinas q tem o prezidente, ministros e officiaes do Tribunal do Dezembargo do Paço", se lee como parte de tales pagos: «Cada dezembargador do Passo de ordenado trez[ien]tos mil reis pagos na alfandega». Por lo menos en el año 1632, fecha de este documento, esta retribución se complementaba con otras sumas menores (propinas) «pella Paschoa de Florez», «Natal», etc.

84 AGS. Secretarías Provinciales, lib. 1459, f. 50, cit. por Santiago de Luxán, La Revolución de 1640 en Portugal, 483. 
favorable a la duquesa de Braganza en la sucesión de la corona portuguesa. Permaneció en su plaza hasta octubre de $1602^{85}$.

\section{CONCLUSIÓN}

En conclusión, cabe afirmar que las medidas aludidas implicaban no sólo perfilar todo un programa de gobierno ante la etapa de incertidumbre iniciada por la ausencia real, sino recuperar las prácticas jurisdiccionales ejercidas por los monarcas responsables de la maduración administrativa de la monarquía portuguesa (D. João II, D. Manuel I y D. João III). Las medidas aludidas perseguían articular y proteger el sistema administrativo basado en la extensión territorial del gobierno doméstico regio. Para ello, resultaba esencial mantener su coherencia interna, basada en la continuidad e integración espacial entre el ámbito decisorio (la Cámara Real), los órganos que transferían las decisiones tomadas (Desembargo, Suplicação, Consejo de Portugal) y el territorio.

En un plano teórico, medidas como la continuación de la audiencia con los órganos jurisdiccionales por parte del Archiduque Alberto y la entrada de dos desembargadores en el Consejo de Portugal parecían determinaciones apropiadas para el indicado propósito. Pero describir con mayor detalle tal planificación y, sobre todo, medir su éxito en el nuevo contexto, requiere un espacio del que aquí carecemos y queda para mejor ocasión.

\footnotetext{
85 Reseñas biográficas de ambos personajes en Santiago Fernández Conti, "Barbosa, Pero", en Felipe II (1527-1598). La configuración de la Monarquía Hispana, dirs. José Martínez Millán-Carlos Javier de Carlos Morales (Salamanca: Junta de Castilla y León, 1998), 331. Así como Henar Pizarro Llorente, "Matos de Noroña, Antonio", en Felipe II (1527-1598), 429. Asimismo, José Antonio Escudero, La creación del Consejo Portugal, 14. Barbosa había formado parte, junto al Chanceler Mor, Paulo Afonso y Lorenzo Correia, de la Junta da Justiça que dio su última forma a las leyes de 27 de junio de 1582, que reformaban la organización jurisdiccional lusa, instituyendo la Casa de Relação de Porto, Nuno J. Espinosa Gomes de Silva, Casa de Relação de História do Direito Português: fontes de Direito (Lisboa: Fundação Calouste Gulbenkian, 2000), 306; Francisco Ribeiro da Silva, "Tradição e inovação na administração da justiça nos primeiros tempos a união ibérica", Revista de História 10 (1990): 67-86. A su vez, Barbosa compiló las Ordenações Filipinas junto a Paulo Afonso, Jorge de Cabedo y Damião de Aguiar, como él desembargadores do paço, Ordenações Filipinas. Livro I (Fundação Calouste Gulbenkian, ed. facsímil de la de Río de Janeiro 1870), LXIII.
} 


\section{BIBLIOGRAFÍA}

Albuquerque, Martim de, O Regimento Quatrocentista da Casa de Suplicação (texto latino acompanhado de tradução portuguesa pelo Dr. Miguel Pinto de Meneses (París: Arquivos do Centro Cultural Português, 1980).

Alves, José da Felicidade, O Mosteiro de São Vicente de Fora (Lisboa: Livros Horizonte, 2008).

Andrade, Francisco de, Crónica de D. João III. Intr. y revisión de M. Luis de Almeida (Porto: Cello e irmão, 1976).

Barata, Maria Themudo, As regencias na menoridade de D. Sebastião. Elementos para uma história estrutural, I (Lisboa: Imprensa Nacional-Casa da Moeda, 1992).

BNE, ms. 2292, "Relación anónima sobre la justicia de Portugal”.

BNP, Cod. 11543, "Repertório do 1", 2", $3^{\circ}$ e $4^{\circ}$ livro dos assentos do Dezembargo do Paço, com o repertório do $1^{\circ}$ livro de consultas, e bum extracto dos Ordenados e propinas q tem o prezidente, ministros e officiaes do Tribunal do Dezembargo do Paşo".

Bouza Álvarez, Fernando, Portugal en la monarquía hispánica (1580-1640). Felipe II, las Cortes de Tomar y la génesis del Portugal católico, I (Madrid: Universidad Complutense, 1987).

Bouza Álvarez, Fernando, "Lisboa sozinha, quase viúva: a cidade e a mudanza da Corte no Portugal dos Filipes", Penélope: revista de história e ciências sociais 13 (1994): 71 94.

Bouza Álvarez, Fernando, "De un fin de siglo a otro. Unión de coronas ibéricas entre Don Manuel y Felipe II", en El Tratado de Tordesillas y su época. Congreso Internacional de Historia, III, La ejecución del Tratado y sus consecuencias (Madrid: Sociedad V Centenario del Tratado de Tordesillas, 1995): 1453-1463.

Brunner, Otto, "La Casa Grande y la Oeconómica de la vieja Europa", en Nuevos caminos de la bistoria social y constitucional (Buenos Aires: Alfa, 1976): 87-123.

Buescu, Ana Isabel, D. João III (Lisboa: Círculo de Leitores-CEPCEP, 2014).

Cabrera de Córdoba, Luis, Historia de Felipe II, Rey de España, II ed. a cargo de José Martínez Millán y Carlos Javier de Carlos Morales (Salamanca: Junta de Castilla y León, 1998). 
Caeiro, Francisco, O Arquiduque Alberto de Austria. Vice-Rei de Portugal (Lisboa: O autor, 1961).

Caetano, Marcelo, Lições de História do Direito Português feitas no curso do $1^{\circ}$ ano da faculdade de Direito, em 1961-1962 (Coimbra: Editora Limitada, 1962).

Caetano, Marcelo, "Desembargo do Paço", Verbo. Enciclopédia Luso-Brasileira de Cultura vol. $6^{\circ}$ (1967): 1095.

Caetano de Sousa, D. António, Provas da História Genealógica da Casa Real Portuguesa. Nova edição revista por M. Lopes de Almeida e César Pegado (Coimbra: Atlántida-Livraria Editora, 1947).

Cardim, Pedro, "La jornada de Portugal y las Cortes de 1619", en La Monarquía de Felipe III: los reinos, José Martínez Millán-María Antonietta Visceglia, dirs. (Madrid: Fundación Mapfre, 2008): 900-946.

Cardim, Pedro, “A Corte régia e o alargamento da esfera privada”, en História da Vida Privada em Portugal. A Idade Moderna, coord., Nuno Gonçalo Monteiro II (Lisboa: Círculo de Leitores, 2011): 160-202.

Cardim, Pedro, "El estatus político de Portugal en la Monarquía Hispana", en Portugal y la Monarquía Hispánica, (ca. 1550-ca. 1715) (Madrid: Marcial Pons, 2017): 4377. https://doi.org/10.2307/j.ctvh4zgbm.4

Carvalho Homem, Armando Luis, O Desembargo Régio (1320-1433) (Portugal: Instituto Nacional de Investigação Científica-Centro de História da Universidade do Porto, 1990).

Checa, Fernando "Un príncipe del Renacimiento. El valor de las imágenes en la Corte de Felipe II", en Felipe II. Un monarca y su época. Un príncipe del Renacimiento Idem, dir. (Madrid: Sociedad Estatal para la Conmemoración de los Centenarios de Felipe II y Carlos V, 1998): 25-26.

Chrónica de ElRei D. Sebastião por Fr. Bernardo da Cruz.publicada por A. Herculano, e O Dr. A.C. Payva (Impressão de Galhardo e irmãos, 1837).

Chueca Goitia, Fernando, "El estilo herreriano y la arquitectura portuguesa", en El Escorial 1563-1963. IV centenario de la fundación del Monasterio de San Lorenzo el Real, 2 (Madrid: Patrimonio Nacional, 1963): 215-262.

Costa Gomes, Rita, The making of a Court Society: Kings and nobles in late medieval Portugal (Cambridge: Cambridge University Press, 2003). https://doi.org/10.1017/CBO9780511523137 
Costa Gomes, Rita, "Les déplacements de la Cour portugaise: deux axiomes et quatre hypothèses pour une comparaison des monarchies iberiques", e-Spania, no. 8 (2009) [http://e-spania.revues.org//8853].

Costa Gomes, Rita, "Le Conseil Royal au Portugal (1400-1520)", en Conseils et conseillers dans l'Europe de la Renaissance, v. 1450-v. 1550, ed. Cedric Michon (Presses Universitaires François Rabelais de Tours- Presses Universitaires de Rennes, 2012):147-174. https://doi.org/10.1017/rqx.2019.149

Crónica do muy alto e muito poderoso rey destes reynos de Portugal dom João o III deste nome. Dirigida ha C.R.M. del Rey dom Felipe o III deste nome nosso senhor. Composta por Francisco d'Andrada do seu Conselho, \& seu Cronista Mor, Anno 1613... Impresa em Lisboa com as licenças necessarias por Iorge Rodríguez.

Cunha, Rodrigo da, História Eclesiástica da Igreja de Lisboa, Lisboa, 1642.

Curto, Diogo Ramada, "Ritos e cerimonias da monarquia em Portugal (séculos XVI a XVIII)", en Francisco Bethencourt-Diogo Ramada Curto, A memória da nação: colóquio do Gabinete de Estudos de Simbologia (Lisboa: Livrária Sa da Costa, 1991):201-265.

Curto, Diogo Ramada, “A cultura política”, en No alvorecer da Modernidade (1480-1620). Vol. III de la História de Portugal dirigida por José Mattoso, coord. Joaquim Romero Magalhaes (Lisboa: Editorial Estampa, 1997): 111-137.

"Desembargo do Paço", Dicionário de História de Portugal. Dirigido por Joel Serrão, vol. I (Porto: Livrária Figueirinhas, 1984).

Ditos portugueses dignos de memória. História intima do século XVI anotada e comentada por José H. Saraiva, $3^{a}$ ed. (Mem Martins: Publicações Europa-América, Lda., 1980).

Escudero, José Antonio, La creación del Consejo de Portugal, Separata do número especial do Boletim da faculdade de Direito de Coimbra "Estudos em Homenagem aos Profs. Manuel Paulo Merêa e Guilherme Braga da Cruz”" (Coimbra: s.n., 1983).

Espinosa Gomes de Silva, Nuno J., História do Direito Português: fontes de Direito (Lisboa: Fundação Calouste Gulbenkian, 2000).

Ezquerra Revilla, Ignacio, "Aportación al estudio de la Junta de Policía (1590-1601)" en Homenaje a Antonio Dominguez Ortiz, Rafael Vázquez Lesmes (Córdoba: Real Academia, 2004):259-282. 
Ezquerra Revilla, Ignacio, "La Cámara", en La monarquía de Felipe II: la Casa del Rey I, dirs. José Martínez Millán-Santiago Fernández Conti (Madrid: Fundación MAPFRE, 2005): 121-142.

Ezquerra Revilla, Ignacio, "Planteamiento de la reforma judicial portuguesa en el contexto de la anexión (1580-1581)", en Las relaciones discretas entre las Monarquias Hispana y Portuguesa: las casas de las reinas (Siglos XV-XIX) coords. José Martínez Millán-Maria Paula Marçal Lourenço (Madrid: Ediciones Polifemo, 2008): 2151-2199.

Ezquerra Revilla, Ignacio, "La Cámara Real como espacio palaciego de integración”, en La Corte de Felipe IV (1621-1665): reconfiguración de la Monarquía Católica I, dirs. José Martínez Millán-José Eloy Hortal Muñoz (Madrid: Polifemo, 2015): 379439.

Ezquerra Revilla, Ignacio, El Consejo Real de Castilla en el espacio cortesano (siglos XVIXVIII) (Madrid: Polifemo, 2017).

Fantoni, Marcello, Gorse, George y Smuts, Malcolm, The Politics of Space: European Courts, ca. 1500-1750 (Roma: Bulzoni Editore, 2009).

Fernández Conti, Santiago, "Barbosa, Pero", en Felipe II (1527-1598). La configuración de la Monarquía Hispana, dirs. José Martínez Millán-Carlos Javier de Carlos Morales (Salamanca: Junta de Castilla y León, 1998): 331.

Fernández Conti, Santiago, "Matos Noronha, Rui de", en Felipe II (1527-1598). La configuración de la Monarquia Hispana; dirs. José Martínez Millán-Carlos Javier de Carlos Morales (Salamanca: Junta de Castilla y León, 1998):429.

Frigo, Daniela, Il padre di famiglia. Governo della casa e governo civile nella tradizione del 'economica' tra Cinque e Seicento (Roma: Bulzoni, 1985).

Frigo, Daniela, "Disciplina Rei Familiariae: a economía como modelo administrativo de Ancien Régime" Penélope. Fazer e desfazer a História 6 (1991): 47-62.

Gama Barros, Henrique de, História da Administração Pública em Portugal nos Séculos XII a XV, III (Lisboa: Livraria Sá da Costa Editora, 1956).

Gambra Gutiérrez, Andrés, "El Palatium y la Domus Regis castellanoleoneses en tiempos de la dinastía pamplonesa", en Evolución y estructura de la Casa Real de Castilla, I coords. Idem-Félix Labrador Arroyo (Madrid: Polifemo, 2010): 11-63. 
Goes, Damião de, Chrónica do felicissimo Rey Dom Emanuel de gloriosa memoria. A qual por mandado do Serenissimo Principe, o Infante Dom Henrique seu filho, o Cardeal de Portugal, do título dos santos quatro coroados, Damião de Gois coligio, e compos de novo. (1619).

González Marrero, María del Cristo, La Casa de Isabel la Católica (Ávila: Institución Gran Duque de Alba, 2005).

Guillaume, Jean (dir.), Architecture et vie sociale. L'Organization intérieure des grandes demeures à la fin du Moyen Age et a la Renaissance (París: Picard, 1994).

Hermano Saraiva, José, História concisa de Portugal (Mira Sintra, 1978).

Herrera, Antonio de, Cinco libros de la historia de Portugaly conquista de las islas de los Açores, en los años 1582 y 1583..., En Madrid, En casa Pedro Madrigal, Año de 1591.

Hespanha, António Manuel, História das Instituções. Épocas medieval e moderna (Coimbra: Almedina, 1982).

Hespanha, António Manuel, “O governo dos Áustria e a 'modernização' da constituição política portuguesa”, Penélope. Faz̧er e desfaz̧er história 2 (1989): 5073.

Hespanha, António Manuel, Visperas del Leviatán. Instituciones y poder político (Portugal, siglo XVII) (Madrid: Taurus, 1989).

Idea de un principe politico christiano, representado en cien empresas, dedicada al Príncipe de las Españas nuestro señor por Don Diego de Saavedra Faxardo..., En Amberes, En casa de Ierónymo y Iuan Bapt. Verdussen, 1655.

Kantorowicz, Ernst H, Los dos cuerpos del rey: un estudio de teología política medieval (Madrid: Alianza Editorial, 1985).

Kubler, Georg, Portuguese plain architecture. Between spices and diamonds (1521-1706) (Middletown [Connecticut]: Wesleyan University Press, 1972).

Labrador Arroyo, Félix, La Casa Real de Portugal (1580-1621) (Madrid: Polifemo, 2009).

Leis extravagantes collegidas e relatadas pelo licenciado Duarte Nunez de Lião, per mandado do muito alto e muito poderoso rei Dom Sebastião nosso senhor, Coimbra: Na Real Imprensa da Universidade. Anno de MDCCLXXXXVI.

Libro primero d'l Espejo del príncipe christiano que trata cómo se ha d'criar un príncepe o niño generoso desde su tierna niñez. con todos los exercicios \& virtudes que le convienen hasta ser 
varón perfecto... por Francisco de Monçon. (Lisboa: en... casa de Luis Rodríguez, 28 Iulio 1544).

Lustre ao Dežembargo do Paço, e as eleições, e perdoens, pertenças de sua jurdição, Dao Ioão Pinto Ribeyro (Lisboa. Com todas as licenças necesarias, Na celebre officina de Paulo Crasbeeck, Anno 1649).

Luxán Meléndez, Santiago de, "La Revolución de 1640 en Portugal: sus fundamentos sociales y sus caracteres nacionales. El Consejo de Portugal, 1580-1640", Tesis Doctoral, presentada en la Universidad Complutense, 1986.

Martínez Millán, José, "Conseillers et factions curiales pendant le règne de l'empereur Charles Quint (1500-1558)" en Conseils et conseillers dans l'Europe de la Renaissance, v. 1450-v. 1550 ed. Cedric Michon, 129-145.

Mayer, Ernst, Historia de las Instituciones Sociales y Politicas de España y Portugal durante los siglos $V$ al XIV, II (Madrid: Anuario de Historia del Derecho Español, 1926; reimp. Scientia Verlag Aalen, 1991).

Moreira, Rafael, “O torreão do Paço da Ribeira”, Mundo da Arte 14 (1983): 43-48.

Moura, Miguel, Cbrónica do Cardeal Rei D. Henrique. Vida de Miguel de Moura escripta por elle mesmo. Publicadas com algunas annotações pela Sociedade propagadora dos conhecimentos utéis (1840).

Murray Baillie, Hugh, "Etiquette and the planning of the state apartments in baroque palaces" en Archaelogia or Miscellaneous Tracts relating to Antiquity 101 (1967): 169199. https://doi.org/10.1017/S0261340900013813

Nieto Soria, José Manuel, "La transpersonalización del poder regio en la Castilla bajomedieval" en Anuario de Estudios Medievales 17 (1987): 559-570.

Ordenações Filipinas. Livro I (Fundação Calouste Gulbenkian, ed. facsímil de la de Río de Janeiro 1870), LXIII.

Ordenações Manuelinas (Lisboa: Fundação Calouste Gulbenkian, 1984).

Pizarro Gómez, Francisco Javier, Arte y espectáculo en los viajes de Felipe II (Madrid: Ediciones Encuentro, 1999).

Pizarro Llorente, Henar, "Matos de Noroña, Antonio", en Felipe II (1527-1598) La configuración de la Monarquia Hispana, dirs. José Martínez Millán-Carlos Javier de Carlos Morales (Salamanca: Junta de Castilla y León, 1998): 429. 
Polo Martín, Regina, Consejos y consultas: la consulta como instrumento de gobierno en la monarquia hispana del Antiguo Régimen: un estudio jurídico institucional con especial referencia al Consejo de Castilla (Madrid: Fundación BBVA, 2018).

Portús Pérez, Javier, "El retrato vivo: fiestas y ceremonias alrededor de un rey y su palacio", en El Real Alcázar de Madrid: dos siglos de arquitectura y coleccionismo en la Corte de los reyes de España dir. Fernando Checa (Madrid: Comunidad de MadridNerea, 1994): 112-130.

Reflexões históricas pelo conselheiro João Pedro Ribeiro, Parte II, Coimbra: na imprensa da Universidade, 1836.

Resende, Garcia de, Chrónica dos valerosos, e insignes feitos del Rey Dom Ioam II de gloriossa memoria, em que se refere sua vida, suas virtudes, seu magnanimo esforço, excellentes costumes, e seu christianissimo zelo, por Garcia de Resende... (Coimbra: Real Officina da Universidade, Anno de MDCCLXXXXVIII).

Ribeiro da Silva, Francisco, "Tradição e inovação na administração da justiça nos primeiros tempos da união ibérica", Revista de História 10 (1990): 67-86.

Ribeiro da Silva, Francisco, Filipe II de Espanha, rei de Portugal (Colectânea de documentos filipinos guardados em Arquivos Portugueses). Estudo introdutório e coordenação de Francisco Ribeiro da Silva, vol. I (Zamora: Fundación Rei Afonso Henriques, 2000).

Salazar y Acha, Jaime de, La Casa del Rey en Castilla y León en la Edad Media (Madrid: Centro de Estudios Constitucionales, 2000).

Sánchez Albornoz, Claudio, "El Palatium Regis asturleonés", Cuadernos de Historia de España 59-60 (1976) 5-77.

Segurado, Jorge, "Juan de Herrera em Portugal", en As relações artísticas entre Portugal e Espanha na época dos decobrimentos (II Simpósio luso-espanhol de História de Arte), coord. Pedro Dias (Coimbra: Livraria Minerva, 1987): 99-111

Senos, Nuno, O paço da Ribeira: 1501-1581 (Lisboa: Editorial Notícias, 2002).

Solnon, Jean Francois, La Cour de France, s.l., 1987.

Starkey, David, The english Court from the Wars of the Roses to the Civil War (Singapore, 1987). 
Suárez Fernández, Luis, "Origen y evolución del Palacio Real en la Edad Media”, en Residencias reales y Cortes itinerantes, VV. AA. (Madrid: Patrimonio Nacional, 1994): 27-34.

Subtil, José, "A administração central da Coroa", en No alvorecer da Modernidade (14801620). Vol. III de la História de Portugal dirigida por José Mattoso, coord. Joaquim Romero Magalhaes (Lisboa: Editorial Estampa, 1997): 75-89.

"Suplicação, Casa da", Dicionário de História de Portugal. Dirigido por Joel Serrão, vol. VI (Porto: Livrária Figueirinhas, 1984).

Synopsis chronologica de subsidios ainda os mais raros para a história e estudo crítico da legislação portuqueza: mandada publicar pela Academia Real das Sciencias de Lisboa e ordenada por José Anastasio de Figueiredo. Tomo II, Desde 1550 até 1603 (Lisboa: na officina da mesma Academia. Anno MDCCXC).

Torres Megiani, Ana Paula, O Rei Ausente: festa e cultura politica nas visitas dos Filipes a Portugal (1581 e 1619) (São Paulo: Alameda Casa Editorial, 2004).

Tratado del gobierno de los Principes, del Doctor Santo Tomás de Aquino, traducida en nuestra lengua castellana por Alonso Ordóñez de Seijas y Tovar, en Madrid, por Iuan González, 1625.

Veiga Testos, Jorge, "O chanceler da Casa de Suplicação e o controlo dos actos dos desembargadores" en Control y responsabilidad de los jueces (Siglos XVI-XXI), coord. José Sánchez-Arcilla Bernal (Madrid: Editorial Dykinson, 2017). https://doi.org/10.2307/j.ctv9zcj91.6

Villacorta Baños-García, Antonio, Don Sebastián Rey de Portugal (Barcelona: Editorial Ariel, 2001).

Warf, Barney y Arias, Santa eds., The Spatial Turn: Interdisciplinary perspectives (London and New York: Routledge, 2009).

Recibido: 4 de septiembre de 2019

Aprobado: 14 de octubre de 2019 